\title{
A Coupling Electromechanical Cell-Based Smoothed Finite Element Method Based on Micromechanics for Dynamic Characteristics of Piezoelectric Composite Materials
}

\author{
Jianxiao Zheng $\mathbb{D}^{1},{ }^{1}$ Zhishan Duan $\mathbb{D}^{1},{ }^{1}$ and Liming Zhou $\mathbb{D}^{2}$ \\ ${ }^{1}$ Yanta Road No. 13, School of Mechanical and Electrical Engineering, Xi'an University of Architecture and Technology, \\ Xi'an 710055, Shaanxi, China \\ ${ }^{2}$ Renmin Street No. 5988, School of Mechanical and Aerospace Engineering, Jilin University, Changchun 130022, Jilin, China
}

Correspondence should be addressed to Jianxiao Zheng; zhengjianxiao1979@163.com

Received 13 January 2019; Revised 22 April 2019; Accepted 28 April 2019; Published 28 May 2019

Guest Editor: Rishi Gupta

Copyright ( $\odot 2019$ Jianxiao Zheng et al. This is an open access article distributed under the Creative Commons Attribution License, which permits unrestricted use, distribution, and reproduction in any medium, provided the original work is properly cited.

Coupling electromechanical cell-based smoothed finite element method (CSFEM) with the asymptotic homogenization method (AHM) is presented to overcome the overstiffness of FEM. This method could accurately simulate the dynamic responses and electromechanical coupling effects of piezoelectric composite material (PCM) structures. Firstly, the efficient performances for active compounds of round cross-section fibers are calculated based on AHM. Secondly, in the CSFEM, electromechanical multiphysic-field FEM is coupled with gradient smoothing technique. CSFEM returns the nearly exact stiffness of continuum structures, which auto discretes the elements in complex areas more readily and thus remarkably reduces the numerical errors. Static and dynamic characteristics of four PCM structures are investigated using CSFEM with AHM. Results are compared with analytical solution and those of FEM, which proves that CSFEM with AHM is more accurate and reliable than the standard FEM when solving problems of complex structures. Additionally, CSFEM could provide results of higher accuracy even using distorted meshes. Therefore, such method is a robust tool for analyzing mechanical properties of PCM structures.

\section{Introduction}

Piezoelectric composite materials (PCMs) could confirm between mechanical energy and electrical energy [1]. PCMs are made of piezoceramics and passive non-piezoelectric polymers $[2,3]$. These composites possess superior properties owing to the most promising characteristics of components as well as various structures.

Because of the electromechanical effects, PCMs are more often used as sensors or actuators into noise, vibration, precision position control, energy harvesting, and structural health monitoring [4-6]. Thus, the electric-mechanical properties of PCMs were investigated widely. The heterogeneous media can be generally characterized by micromechanical models. Under such scenario, numerical or analytical ways were used to electromechanically characterize PCMs.
Some analytical approaches were presented to investigate PCMs, but the methods were limited by boundary conditions and loading cases $[7,8]$. Moreover, single inclusion was applied into a piezoelectric material based on the micromechanical theory with the electromechanical solution [9-13]. Also, the asymptotic homogenization method (AHM) was developed to solve the effective coefficients of PCMs with the square fibers distribution $[14,15]$. AHM can be used to calculate effective performances of structures made of hexagonal symmetrical and randomly distributed fibers $[16,17]$. The effective elastic coefficients of periodic composites could be solved by an asymptotic method [18]. Otero et al. expressed the effective properties of reinforced PCMs in the closed form [19]. de Medeiros et al. studied the effective coefficients of PCMs made of circular or squared cross-sectional fibers based on AHM [20]. Viaño et al. derived a high-order asymptotic 
expanding model of piezoelectric rods [21]. Le built an exact $2 \mathrm{D}$ theory based on the variation asymptotic method for functionally graded PCMs [22]. Fantoni et al. proposed a multifield AHM to analyze the periodic microstructured PCMs exposed to body force, charge density, and heat sources [23]. However, closed-form solutions which are very a valuable benchmark to issues concerning PCMs are often inaccessible except for relatively simple boundary and geometry conditions.

Among numerical approaches, researchers usually use the finite element model (FEM) to develop a specific representative volume element (RVE) for various physical problems, including piezoelectricity. Kar-Gupta and Venkatesh developed an FEM to evaluate how the fiber form affected the general piezoelectric characteristic of PCMs [24]. Jin et al. developed a micromechanical model based on linear stress strain relations and the stress amplification factor to determine the microstress under various mechanical loadings [25]. de Medeiros et al. compared the analytical model and FEM with RVEs in calculating the effective coefficients of PCMs [20]. Würkner et al. established a numerical model to estimate the effective indexes of unidirectional fiber-reinforced PCMs with rhombic fiber arrangement [26]. Mishra et al. extended FEM to evaluate the effective properties of PCMs with SU8 photoresist as the matrix reinforced by the vertically arrayed $\mathrm{ZnO}$ nanowires [27]. Bowen et al. discussed the effective properties of new PCMs based on ferroelectric PCR-7M ceramic [28]. Though most of the FEMs can interpolate displacement and electric potential as kinematic field indicators with satisfactory compatibility equations, these methods are often limited by overly stiffness, inaccuracy, and sensitivity to mesh distortion. These limitations can be overcome by hybrid and mixed finite elements [29-32]. Other contributions include drilling degree-of-freedom piezoelectric elements [33-35]. For details and review on FEM establishment for PCM analysis and modeling, refer to Reference [36]. So far, much research has been conducted to develop new special elements [12,37]. However, the application of FEM is yet limited by the occurrence of mesh distortion.

To solve the problem of mesh distortion in FEM, Liu et al. presented a new smoothed FEM by incorporating the gradient smoothing technique (GST) into FEM for solid mechanics problems, based on the nodal integrated meshless methods [38-42]. The FEM employs standard Galerkin formulation in which the stiffness matrix is stiffened by the presumed displacement field [43]. In the smoothed FEM, the smoothed Galerkin weak form is used where GST softens the stiffness matrix through the softening effect. Theoretically, the smoothed FEM in the energy norm often creates a softer stiffness matrix than the FEM with the same background meshes [44, 45]. This unique ability endows smoothed FEM with many critical characteristics [46], such as the easier modeling, upper bound solution property [47], and even nearly perfect solutions in a norm [43, 48-52]. The softening effects enable smoothed FEM to process highly distorted meshes and $n$-sided polygonal elements [45]. The smoothed FEM interpolates displacement according to the same lower standard mesh and evaluates the weak form based on the smoothing zones.

An ultraprecise hybrid smoothed FEM for the piezoelectric problem was designed using with the simplest three- and four-sided elements in $2 \mathrm{D}$ and $3 \mathrm{D}$, respectively [53]. An edge-based smoothed FEM was proposed for static eigenvalue assessment of $2 \mathrm{D}$ piezoelectric structures [54]. An effective numerical method was presented to optimize and maximize the basic frequency of functionally graded carbon-nanotube-strengthened four-sided sheets [55]. On the commercial software ABAQUS, Bhowmick and Liu established a phase-field model based on cellbased smoothed FEM (CSFEM) to address the brittle fracturing in solids [56]. Pramod et al. developed the CSFEM with the Reissner's mixed variational theorem to analyze the static and free vibration of cross-ply sheet plates [57].

In this work, the dynamic characteristics on PCM structures were studied by using the technique based on the effective CSFEM with AHM. Longitudinal/transversal elastic, piezoelectric, and dielectric effective parameters of a piezoceramic fiber with an $\mathrm{O}$-shaped geometrical section buried in a non-piezoelectric material were computed by AHM based on micromechanics. The CSFEM of PCM structures was presented by applying GST into the exit FEM for an electromechanical coupling field. Then, the equations of the dynamic responses under the multifield for PCM instruments were deduced. Finally, a bilayered PCM actuator and a PCM energy harvester based on micromechanics were calculated by CSFEM. Results of CSFEM were compared with those of FEM, which validated that CSFEM possessed the advantages of accuracy, convergence, and efficiency. Besides, CSFEM was insensitive to mesh distortion, which was very useful to analyze complex structures or large deformation problems. Therefore, CSFEM with AHM performed better than FEM.

This paper is organized as follows: Section 2 introduces the basic formulations for PCMs. Sections 3 and 4 describe the AHM based on micromechanics and CSFEM, respectively. Section 5 puts forward the modified Wilson- $\theta$ method. In Section 6, the bilayered PCM actuator and the PCMs energy harvester were elaborated. Section 7 gives the conclusions.

\section{Basic Equations for PCMs}

2.1. Geometry and Coordinate System. The cross section of a PCM beam was a rectangle with length $L$, breadth $b$, and height $h$. Here, the continuum theory was used. The PCMs, cylindrical piezoceramic fibers, were buried in the epoxy substrate. The Cartesian coordinate system $\left(x_{1}, x_{2}, x_{3}\right)$ and geometric parameters are illustrated in Figure 1.

2.2. Constitutive Equations. The $3 \mathrm{D}$ linear constitutive equations, which can very accurately model the 


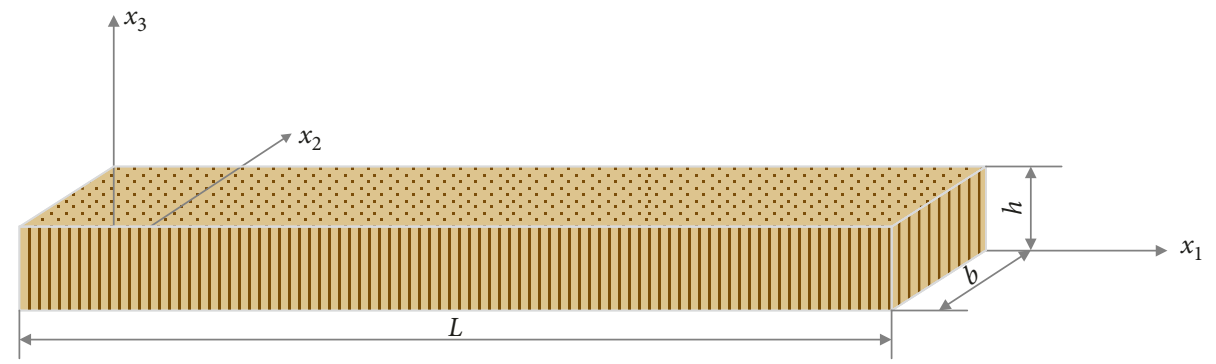

Figure 1: A PCMs beam: geometric parameters and Cartesian coordinate system.

electromechanical coupling behavior of PCMs, are polarized along the global coordinates as follows:

$$
\begin{aligned}
& {\left[\begin{array}{l}
\sigma_{11} \\
\sigma_{22} \\
\sigma_{33} \\
\sigma_{23} \\
\sigma_{13} \\
\sigma_{12}
\end{array}\right]=\left[\begin{array}{cccccc}
c_{11} & c_{12} & c_{13} & 0 & 0 & 0 \\
c_{12} & c_{22} & c_{23} & 0 & 0 & 0 \\
c_{13} & c_{23} & c_{33} & 0 & 0 & 0 \\
0 & 0 & 0 & c_{44} & 0 & 0 \\
0 & 0 & 0 & 0 & c_{55} & 0 \\
0 & 0 & 0 & 0 & 0 & c_{66}
\end{array}\right]\left[\begin{array}{c}
\varepsilon_{11} \\
\varepsilon_{22} \\
\varepsilon_{33} \\
2 \varepsilon_{23} \\
2 \varepsilon_{13} \\
2 \varepsilon_{12}
\end{array}\right]} \\
& -\left[\begin{array}{ccc}
0 & 0 & e_{31} \\
0 & 0 & e_{32} \\
0 & 0 & e_{33} \\
0 & e_{24} & 0 \\
e_{15} & 0 & 0 \\
0 & 0 & 0
\end{array}\right]\left[\begin{array}{c}
E_{1} \\
E_{2} \\
E_{3}
\end{array}\right] \\
& {\left[\begin{array}{l}
D_{1} \\
D_{2} \\
D_{3}
\end{array}\right]=\left[\begin{array}{cccccc}
0 & 0 & 0 & 0 & e_{15} & 0 \\
0 & 0 & 0 & e_{24} & 0 & 0 \\
e_{31} & e_{32} & e_{33} & 0 & 0 & 0
\end{array}\right]\left[\begin{array}{c}
\varepsilon_{11} \\
\varepsilon_{22} \\
\varepsilon_{33} \\
2 \varepsilon_{23} \\
2 \varepsilon_{13} \\
2 \varepsilon_{12}
\end{array}\right]} \\
& +\left[\begin{array}{ccc}
\chi_{11} & 0 & 0 \\
0 & \chi_{22} & 0 \\
0 & 0 & \chi_{33}
\end{array}\right]\left[\begin{array}{l}
E_{1} \\
E_{2} \\
E_{3}
\end{array}\right],
\end{aligned}
$$

where $\sigma_{i j}$ and $\varepsilon_{k l}$ are the stress and infinitesimal strain tensors, respectively; $E_{i}$ and $D_{i}$ are electric field and electric displacement vector components, respectively; $e_{i k}, c_{k l}$, and $\chi_{i j}$ are the piezoelectric, elastic, and dielectric material constants, respectively.

In the PCM beam, equations (1) and (2) could be written in the matrix form:

$$
\begin{gathered}
\boldsymbol{\sigma}=\mathbf{C} \boldsymbol{\varepsilon}-\mathbf{e E}, \\
\mathbf{D}=\mathbf{e}^{\mathrm{T}} \boldsymbol{\varepsilon}+\chi \mathbf{E},
\end{gathered}
$$

where

$$
\begin{aligned}
\boldsymbol{\sigma} & =\left[\begin{array}{l}
\sigma_{11} \\
\sigma_{33} \\
\sigma_{13}
\end{array}\right], \\
\mathbf{C} & =\left[\begin{array}{lll}
c_{11} & c_{13} & 0 \\
c_{31} & c_{33} & 0 \\
0 & 0 & c_{55}
\end{array}\right], \\
\mathbf{e} & =\left[\begin{array}{ll}
0 & e_{31} \\
0 & e_{33} \\
e_{15} & 0
\end{array}\right], \\
\mathbf{E} & =\left[\begin{array}{l}
E_{1} \\
E_{3}
\end{array}\right], \\
\boldsymbol{\varepsilon} & =\left[\begin{array}{l}
\varepsilon_{11} \\
\varepsilon_{33} \\
\varepsilon_{13}
\end{array}\right], \\
\mathbf{D} & =\left[\begin{array}{l}
D_{1} \\
D_{3}
\end{array}\right], \\
\chi & =\left[\begin{array}{ll}
\chi_{11} & 0 \\
0 & \chi_{33}
\end{array}\right] .
\end{aligned}
$$

The balance law and Gauss' law underlie the description of the coupled field responses, and in the case of no body force and for quasistatic electromechanics, equations can be expressed as

$$
\begin{aligned}
\sigma_{j i, j} & =0, \\
\sigma_{j i} & =\sigma_{i j}, \\
D_{i, i} & =0 .
\end{aligned}
$$

The boundary conditions are as follows: For the mechanical fields,

$$
\begin{aligned}
u_{i}(t) & =\bar{u}_{i}(t) \text { on } \Gamma_{u}, \\
\sigma_{i j} n_{j} & =\bar{\beta}_{i}(t) \text { on } \Gamma_{\beta}, \\
\Gamma & =\Gamma_{u} \cup \Gamma_{\beta} .
\end{aligned}
$$




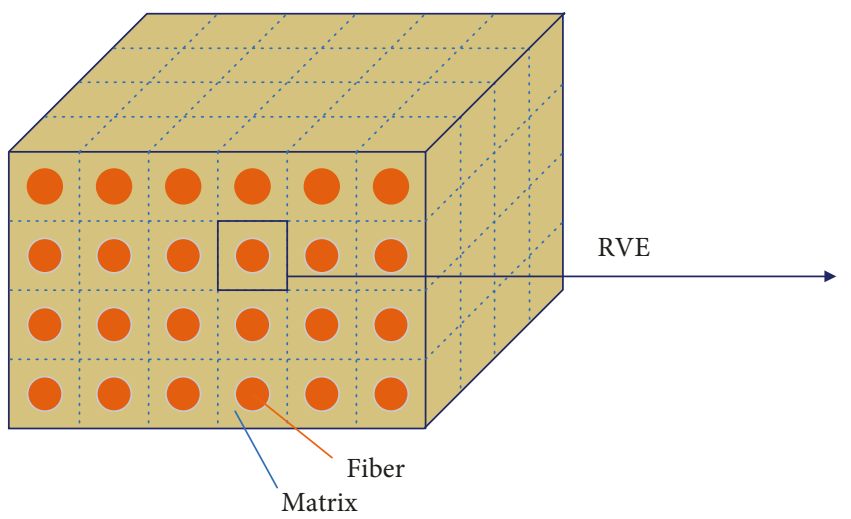

(a)

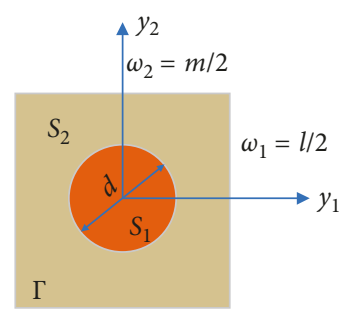

(c)

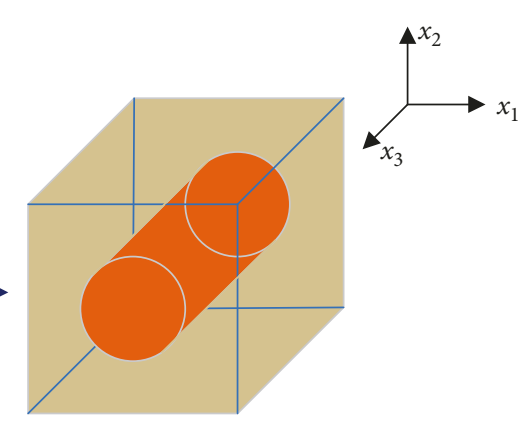

(b)

Figure 2: The geometric mode of PCMs: (a) structure, (b) representative volume element (RVE), and (c) transversal cross-section of the RVE.

For the electric fields,

$$
\begin{aligned}
\boldsymbol{\Phi}(t) & =\overline{\boldsymbol{\Phi}}(t) \text { on } \Gamma_{p}, \\
D_{i} n_{i} & =\bar{Q}(t) \text { on } \Gamma_{b}, \\
\Gamma & =\Gamma_{a} \cup \Gamma_{b},
\end{aligned}
$$

where $\Gamma, \bar{u}_{i}(t)$, and $\bar{\Phi}(t)$ are the global boundary, displacement, and electrical potential, respectively; $\Gamma_{u}, \Gamma_{\beta}, \Gamma_{p}$, and $\Gamma_{q}$ are the prescribed displacement, traction vector, normal component of the electric displacement vector, and electrical potential of $\Gamma$, respectively; $\bar{\beta}_{i}(t)$ and $\bar{Q}(t)$ are the surface load and surface density of free charge, respectively.

\section{AHM}

A fiber and matrix two-phase structure (Figure 2(a)) is defined by a composite body $\Omega$ and the axis $x_{3}$ parallel to the fibers. Straight reinforcement is periodically arranged. Hence, RVE could be illustrated in Figure 2(b). The periodic cell $S$ has a squared transversal, which includes a circle of radius $R$ (Figure 2(c)).

The phases are supposed to be homogeneous and electroelastically linear. Between the fiber and the matrix is the interface $\Gamma$, which is regarded as perfect. In the composite, the dimensions $l$ and $L$ are the fiber diameter and the center-to-center distance between two adjacent cylinders (fibers), respectively. Since $\varepsilon=l / L$ is far smaller than the dimension of RVE, two space scales the slow variable $x$ and the fast variable $y=x / \varepsilon$, can be separated. The stress and strain tensors, electrical displacement vector, and electric potential are continuous across $\Gamma$ or namely between phases. Thus, $C_{k l}, e_{i k}$, and $\chi_{i j}$ have piecewise constant roles in the periodic cells.
The first set of math issues has new physical relationships over $\Omega$ with mechanical $(\bar{C})$, piezoelectric $(\bar{e})$, and dielectric $(\bar{\chi})$ constant coefficients, which reflect the characteristics of a uniform medium $\Omega$ and are called the effective characteristics of PCMs (Figure 2). The coefficients $\bar{c}_{i j p q}, \bar{e}_{i p q}$, and $\bar{\chi}_{i p}$ could be computed using the equations in Reference [14].

\section{Electromechanical CSFEM}

4.1. Weak Formulation. The virtual work for a piezoelectric material with volume $\Omega$ and regular boundary surface $\Gamma$ can be expressed as

$$
\begin{aligned}
\delta \Pi= & \delta U-\delta W=-\int_{\Omega} \delta \bar{\varepsilon}^{\mathrm{T}} \boldsymbol{\sigma} d \Omega+\int_{\Gamma} \delta \mathbf{u}^{\mathrm{T}} \bar{\beta} d \Gamma \\
& +\int_{\Omega} \rho \delta \mathbf{u}^{\mathrm{T}} \ddot{\mathbf{u}} d \Omega+\int_{\Omega} \delta \bar{E}^{\mathrm{T}} \mathbf{D} d \Omega+\int_{\Gamma} \bar{Q} \delta \boldsymbol{\Phi} d \Gamma=0,
\end{aligned}
$$

where $\rho$ and $\delta$ are mass density and virtual quantity, respectively. $\Omega$ is divided into $n_{p}$ elements, which contains $N_{n}$ nodes, and the approximation displacement $\overline{\mathbf{u}}$ and electrical potential $\bar{\Phi}$ for an FGPM problem can be expressed as

$$
\begin{gathered}
\bar{u}=\sum_{i=1}^{n_{p}} N_{i}^{u} u_{i}=\mathbf{N}_{u} \mathbf{u}, \\
\bar{\Phi}=\sum_{i=1}^{n_{p}} N_{i}^{\Phi} \Phi_{i}=\mathbf{N}_{\Phi} \Phi,
\end{gathered}
$$

where $\mathbf{N}_{u}$ and $\mathbf{N}_{\Phi}$ are the shape functions of electromechanical CSFEM displacement and electrical potential, respectively. 
A 4-node element is separated into four smoothing subdomains $\Omega_{i}^{k}$. The nodes of field and edge/center smoothing, the edge Gaussian points, outer normal vector distribution, and the shape functions are shown in Figure 3.

At any point $\mathbf{x}^{k}$ in $\Omega_{i}^{k}$, the smoothed form of strain $\bar{\varepsilon}\left(\mathbf{x}^{k}\right)$ and electric field $\bar{E}\left(\mathbf{x}^{k}\right)$ are

$$
\begin{aligned}
\bar{\varepsilon}\left(\mathbf{x}^{k}\right) & =\int_{\Omega_{i}^{k}} \boldsymbol{\varepsilon}(\mathbf{x}) r\left(\mathbf{x}-\mathbf{x}^{k}\right) d \Omega, \\
\bar{E}\left(\mathbf{x}^{k}\right) & =\int_{\Omega_{i}^{k}} \mathbf{E}(\mathbf{x}) r\left(\mathbf{x}-\mathbf{x}^{k}\right) d \Omega,
\end{aligned}
$$

where $r\left(\mathbf{x}-\mathbf{x}^{k}\right)$ is the constant function:

$$
r\left(\mathbf{x}-\mathbf{x}^{k}\right)= \begin{cases}1 / A_{i}^{k}, & \mathbf{x} \in \Omega_{i}^{k}, \\ 0, & \mathbf{x} \notin \Omega_{i}^{k},\end{cases}
$$

where

$$
A_{i}^{k}=\int_{\Omega_{i}^{k}} d \Omega .
$$

Substituting equation (12) in equations (10) and (11), we have

$$
\begin{gathered}
\bar{\varepsilon}\left(\mathbf{x}_{k}\right)=\frac{1}{A_{i}^{k}} \int_{\Gamma_{i}^{k}} \mathbf{n}_{u}^{k} \mathbf{u} d \Gamma, \\
\bar{E}\left(\mathbf{x}_{k}\right)=\frac{1}{A_{i}^{k}} \int_{\Gamma_{i}^{k}} \mathbf{n}_{\Phi}^{k} \Phi d \Gamma,
\end{gathered}
$$

where $\Gamma_{i}^{k}$ is the boundary of $\Omega_{i}^{k}$ and $\mathbf{n}_{u}^{k}$ and $\mathbf{n}_{\Phi}^{k}$ are the outer normal vector matrices of the smoothing domain boundary:

$$
\begin{aligned}
\mathbf{n}_{u}^{k} & =\left[\begin{array}{cc}
n_{x_{1}}^{k} & 0 \\
0 & n_{x_{3}}^{k} \\
n_{x_{3}}^{k} & n_{x_{1}}^{k}
\end{array}\right], \\
\mathbf{n}_{\Phi}^{k} & =\left[\begin{array}{c}
n_{x_{1}}^{k} \\
n_{x_{3}}^{k}
\end{array}\right] .
\end{aligned}
$$

Equations (14) and (15) can be newly expressed as

$$
\begin{aligned}
& \bar{\varepsilon}\left(\mathbf{x}^{k}\right)=\sum_{i=1}^{n_{\mathrm{e}}} \bar{B}_{u}^{i}\left(\mathbf{x}^{k}\right) \mathbf{u}_{i}, \\
& \bar{E}\left(\mathbf{x}^{k}\right)=-\sum_{i=1}^{n_{\mathrm{e}}} \bar{B}_{\Phi}^{i}\left(\mathbf{x}^{k}\right) \boldsymbol{\Phi}_{i},
\end{aligned}
$$

where $n_{\mathrm{e}}$ is the number of smoothing elements.

$$
\begin{aligned}
& \bar{B}_{u}^{i}\left(\mathbf{x}^{k}\right)=\frac{1}{A_{i}^{k}} \int_{\Gamma^{k}}\left[\begin{array}{cc}
N_{i}^{u} n_{x_{1}}^{k} & 0 \\
0 & N_{i}^{u} n_{x_{3}}^{k} \\
N_{i}^{u} n_{x_{3}}^{k} & N_{i}^{u} n_{x_{1}}^{k}
\end{array}\right] d \Gamma, \\
& \bar{B}_{\Phi}^{i}\left(\mathbf{x}^{k}\right)=\frac{1}{A_{i}^{k}} \int_{\Gamma^{k}}\left[\begin{array}{c}
N_{i}^{\Phi} n_{x_{1}}^{k} \\
N_{i}^{\Phi} n_{x_{3}}^{k}
\end{array}\right] d \Gamma,
\end{aligned}
$$

At the Gaussian point $\mathbf{x}_{b}^{\mathrm{G}}$, equations (18) and (19) become

$$
\begin{aligned}
& \bar{B}_{u}^{i}\left(\mathbf{x}^{k}\right)=\frac{1}{A_{i}^{k}} \sum_{b=1}^{n_{b}}\left(\begin{array}{cc}
N_{i}^{u}\left(\mathbf{x}_{b}^{\mathrm{G}}\right) n_{x_{1}}^{k} & 0 \\
0 & N_{i}^{u}\left(\mathbf{x}_{b}^{\mathrm{G}}\right) n_{x_{3}}^{k} \\
N_{i}^{u}\left(\mathbf{x}_{b}^{\mathrm{G}}\right) n_{x_{3}}^{k} & N_{i}^{u}\left(\mathbf{x}_{b}^{\mathrm{G}}\right) n_{x_{1}}^{k}
\end{array}\right) l_{b}^{k}, \\
& \bar{B}_{\Phi}^{i}\left(\mathbf{x}^{k}\right)=\frac{1}{A_{i}^{k}} \sum_{b=1}^{n_{b}}\left(\begin{array}{c}
N_{i}^{\Phi}\left(\mathbf{x}_{b}^{\mathrm{G}}\right) n_{x_{1}}^{k} \\
N_{i}^{\Phi}\left(\mathbf{x}_{b}^{\mathrm{G}}\right) n_{x_{3}}^{k}
\end{array}\right) l_{b}^{k},
\end{aligned}
$$

where $l_{b}^{k}$ is the length of the smoothing boundary and $n_{\mathrm{b}}$ is the total number of boundaries in a subdomain. As the shape function varies linearly along each side of the subdomain, one Gauss point is enough for precise boundary integration [38].

The essential distinction between CSFEM and FEM is that FEM needs to construct the shape function matrix of the element, while CSFEM only needs to use the function at the Gaussian point of the smoothing element boundary and avoids the function derivatives, which reduces the continuity requirement of the shape function and improves the accuracy and convergence.

The dynamic model of the PCM electromechanical system can be deduced from the Hamilton rule as follows:

$$
\bar{M} \ddot{\mathbf{q}}+\bar{K} \mathbf{q}=\bar{F},
$$

where

$$
\begin{aligned}
\bar{M} & =\left[\begin{array}{cc}
\mathbf{M}_{u u} & 0 \\
0 & 0
\end{array}\right], \\
\ddot{q} & =\left\{\begin{array}{l}
\ddot{u} \\
\ddot{\Phi}
\end{array}\right\}, \\
\bar{K} & =\left[\begin{array}{ll}
\mathbf{K}_{u u} & \mathbf{K}_{u \Phi} \\
\mathbf{K}_{u \Phi}^{\mathrm{T}} & \mathbf{K}_{\Phi \Phi}
\end{array}\right], \\
\mathbf{q} & =\left\{\begin{array}{l}
\mathbf{u} \\
\mathbf{\Phi}
\end{array}\right\}, \\
\bar{F} & =\left\{\begin{array}{l}
\mathbf{F} \\
\mathbf{Q}
\end{array}\right\}, \\
\mathbf{M}_{u u} & =\sum_{e} \mathbf{M}_{u u}^{e}, \\
\mathbf{M}_{u u}^{e} & =\operatorname{diag}\left\{m_{1}, m_{1}, m_{2}, m_{2}, m_{3}, m_{3}, m_{4}, m_{4}\right\},
\end{aligned}
$$

where $m_{i}=p_{i} T, A_{i}^{k}(i=1,2,3,4)$ is the mass of the $i$-th smoothing element related to node $i, T$ is the smoothing element thickness, and $p_{i}$ is the density of the Gaussian integration point of the $i$-th smoothing subdomain. 


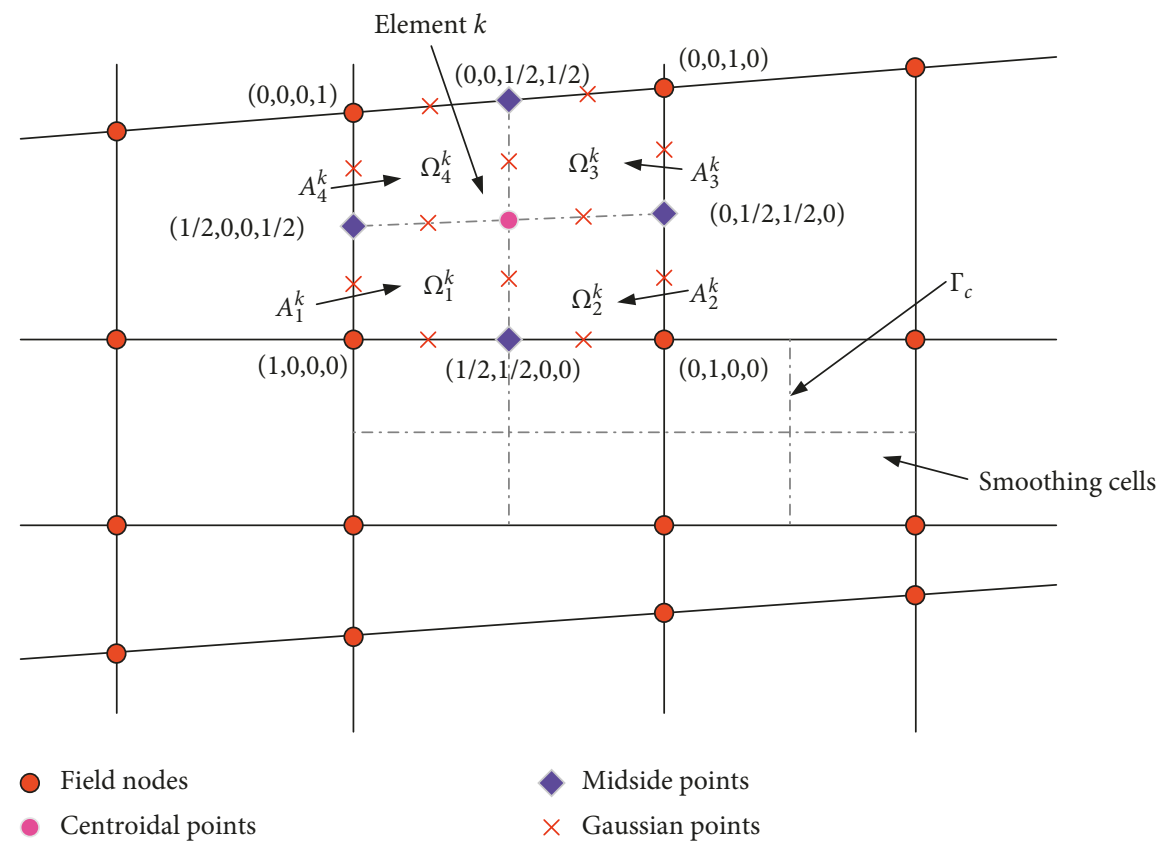

Figure 3: Smoothing subcells and the values of shape functions.

$$
\begin{aligned}
\mathbf{K}_{u u} & =\sum_{i=1}^{n_{c}} \bar{B}_{u}^{i \mathrm{~T}} \bar{C} \bar{B}_{u}^{i} A_{i}^{k}, \\
\mathbf{K}_{u \Phi} & =\sum_{i=1}^{n_{c}} \bar{B}_{u}^{i \mathrm{~T}} \overline{\bar{e}} \bar{B}_{\Phi}^{i} A_{i}^{k}, \\
\mathbf{K}_{\Phi \Phi} & =-\sum_{i=1}^{n_{c}} \bar{B}_{\Phi}^{i \mathrm{~T}} \bar{\chi} \bar{B}_{\Phi}^{i} A_{i}^{k}, \\
\mathbf{F} & =\int_{\Gamma_{q}} \mathbf{N}_{u}^{\mathrm{T}} \boldsymbol{\beta} d \Gamma, \\
\mathbf{Q} & =\int_{\Omega} \mathbf{N}_{\Phi}^{\mathrm{T}} \overline{\mathbf{Q}} d \Omega,
\end{aligned}
$$

(3) Select the time step $\Delta t$ and the integral constant $\theta$ $(\theta=1.4)$

$$
\begin{aligned}
& a_{0}=\frac{6}{(\theta \Delta \mathrm{t})^{2}}, \\
& a_{1}=\frac{3}{(\theta \Delta \mathrm{t})}, \\
& a_{2}=2 a_{1}, \\
& a_{3}=\frac{\theta \Delta \mathrm{t}}{2}, \\
& a_{4}=\frac{a_{0}}{\theta}, \\
& a_{5}=-\frac{a_{2}}{\theta}, \\
& a_{6}=1-\frac{3}{\theta}, \\
& a_{7}=\frac{\Delta t}{2}, \\
& a_{7}=\frac{\Delta t}{2}, \\
& a_{8}=-\frac{\Delta t^{2}}{6} .
\end{aligned}
$$

The modified Wilson- $\theta$ method is an important scheme and an implicit integral way to solve the dynamic system equations. If $\theta>1.37$, the solution is unconditionally stable. The detailed procedures are shown as follows.

\subsection{Initial Calculation}

(1) Formulate generalized stiffness matrix $\bar{K}$, mass matrix $\bar{M}$

(2) Calculate initial values of $\mathbf{u}, \dot{u}, \ddot{u}$

(4) Formulate an effective generalized stiffness matrix $\widetilde{K}$ : $\widetilde{K}=\bar{K}+a_{0} \bar{M}$. 


\subsection{For Each Time Step}

(1) Calculate the payload at time $t+\theta \Delta t$ :

$$
\bar{F}_{t+\theta \Delta t}=\bar{F}_{t}+\theta\left(\bar{F}_{t+\Delta t}-\bar{F}_{t}\right)+\bar{M}\left(a_{0} \mathbf{q}_{t}+a_{2} \dot{\mathbf{q}}_{t}+2 \ddot{\mathbf{q}}_{t}\right) .
$$

(2) Calculate the generalized displacement at time $t+\theta \Delta t$

$$
\widetilde{K} \mathbf{u}_{t+\theta \Delta t}=\bar{F}_{t+\theta \Delta t} .
$$

(3) Calculate the generalized acceleration, generalized speed, and generalized displacement at time $t+\Delta t$ :

$$
\begin{aligned}
& \ddot{\mathbf{u}}_{t+\Delta t}=a_{4}\left(\mathbf{u}_{t+\theta \Delta t}-\mathbf{u}_{t}\right)+a_{5} \dot{\mathbf{u}}_{t}+a_{6} \ddot{\mathbf{u}}_{t}, \\
& \dot{\mathbf{u}}_{t+\Delta t}=\dot{\mathbf{u}}_{t}+a_{7}\left(\ddot{\mathbf{u}}_{t+\Delta t}+\ddot{\mathbf{u}}_{t}\right), \\
& \mathbf{u}_{t+\Delta t}=\mathbf{u}_{t}+\Delta t \dot{\mathbf{u}}_{t}+a_{8}\left(\ddot{\mathbf{u}}_{t+\Delta t}+2 \ddot{\mathbf{u}}_{t}\right) .
\end{aligned}
$$

\section{Numerical Results}

6.1. A Singer-Player PCMs Strip. In this example to test the precision of CSFEM under mechanical and electrical boundary conditions, we used the shear deformation of a piezoelectric strip $\left(1 \times 1 \mathrm{~mm}^{2}\right.$, thickness $\left.t=10 \mu \mathrm{m}\right)$ under compressive stress $\sigma_{0}=5 \mathrm{~N} \cdot \mathrm{mm}^{-2}$ and applied voltage $V_{0}=$ $1000 \mathrm{~V}$ (Figure 4). The PCMs, piezoceramic fibers (PZT-5A), were buried in the non-piezoelectric epoxy matrix. The material properties are shown in Table 1 [20]. A block of 10000 square cells (each cell $10 \times 10 \times 10 \mu \mathrm{m}^{3}$ ) was used in the composite $z$ with the specific fiber volume fraction of $55.55 \%$. One part of the PCM structure $\left(60 \times 10 \times 40 \mu \mathrm{m}^{3}\right)$ is shown in Figure 5. The materials were polarized under the electric field set to the left and right edges, which resulted in shear strain. The boundary conditions were applied to the strip edges:

$$
\begin{gathered}
\Phi_{, z}(x, z= \pm h)=0, \\
\sigma_{z z}(x, z= \pm h)=\sigma_{0}, \\
\sigma_{x z}(x=L, z)=0, \\
\sigma_{x z}(x, z= \pm h)=0, \\
\Phi(x=L, z)=-V_{0}, \\
\sigma_{x x}(x=L, z)=0, \\
\Phi(x=0, z)=V_{0}, \\
u(x=0, z)=0, \\
v(x=0, z=0)=0 .
\end{gathered}
$$
[58]:

The analytical solution to this problem is shown below

$$
\begin{aligned}
& u=s_{13} \sigma_{0} x, \\
& v=\frac{d_{15} V_{0} x}{h}+s_{33} \sigma_{0} z, \\
& \boldsymbol{\Phi}=V_{0}\left(1-\frac{2 x}{L}\right) .
\end{aligned}
$$

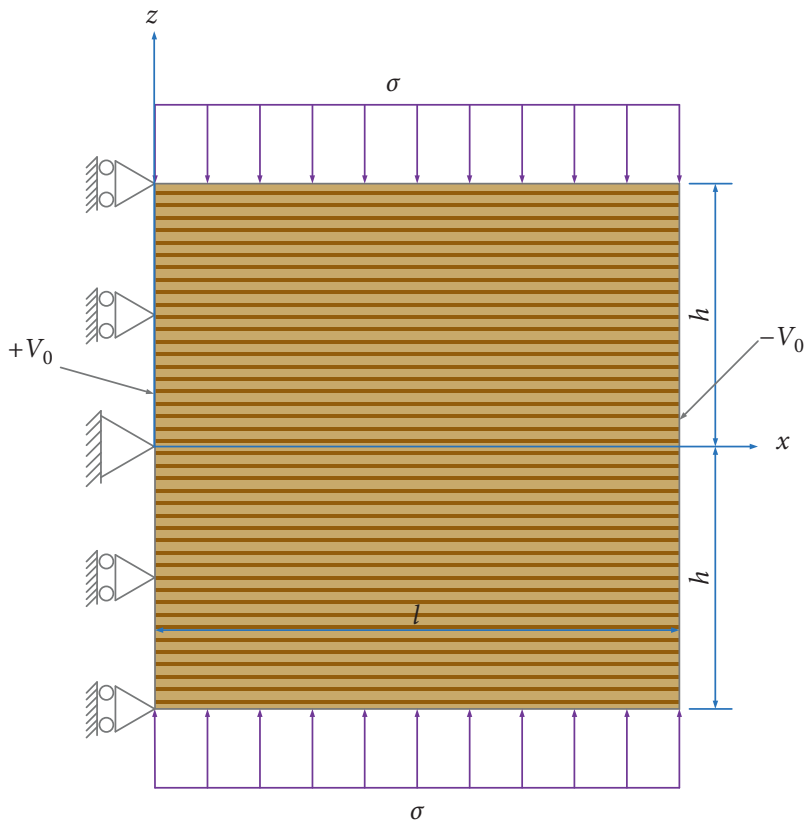

FIGURE 4: A singer-player PCMs strip under shear deformation.

It should be noted that all 11 effective coefficients in Table 2 were determined using AHM. CSFEM, FEM, and analytical solution were all based on AHM. Three meshes (each $10 \times 10$, including one with uniform elements and two with distorted elements) were analyzed by CSFEM (Figure 6). The $\alpha_{\mathrm{ir}}$ is the irregularity factor that is assigned between 0.0 and 0.5 [38]. Meanwhile, $60 \times 60$ uniform elements were used by FEM. Figure 7 illustrates the CSFEM, FEM, and analytical horizontal displacement $u_{x}$ at the central line $(z=0)$, while the vertical displacement $u_{z}$ at $z=0$ of the single-layer PCM strip is shown in Figure 8. The distributions of the electric potential $\Phi$ at $z=0$ with FEM and the analytical solutions are demonstrated in Figure 9. Clearly, the displacements and electric potential computed by CSFEM match well with the analytical solutions and outperform those estimated by FEM for all three meshes, which suggested that CSFEM can recreate the linear behavior of the analytical solutions.

Moreover, the computation cost of CSFEM over PCMs in a homogenized structure surpasses that of FEM with a heterogeneous structure (Figure 10), but FEM costs more to reach the same precision. Thus, CSFEM clearly enhances the calculation efficiency.

A comparison of costs (computation time for the same accuracy) for the homogenized PCM structures indicates CSFEM takes much lower cost than traditional FEM.

6.2. A Cantilever PCMs Beam. The free vibrations on a cantilever PCM beam were calculated by CSFEM under the geometrical parameters of length $L=20 \mathrm{~mm}$, width $H=2 \mathrm{~mm}$, and plane stress (Figure 11). The PCMs, piezoceramic fibers (PZT-5A), were buried in the nonpiezoelectric epoxy matrix. The material properties are shown in Table 3. A block of 16000 square cells was used in the composite $z$ with the specific fiber volume fraction of 
TABLE 1: Material constants for constituents of the PZT-5A and epoxy matrix.

\begin{tabular}{|c|c|c|c|c|c|c|c|c|c|c|c|c|}
\hline Material & $\begin{array}{c}c_{11} \\
(\mathrm{GPa})\end{array}$ & $\begin{array}{c}c_{12} \\
(\mathrm{GPa})\end{array}$ & $\begin{array}{c}c_{13} \\
(\mathrm{GPa})\end{array}$ & $\begin{array}{c}c_{33} \\
(\mathrm{GPa})\end{array}$ & $\begin{array}{c}c_{44} \\
(\mathrm{GPa})\end{array}$ & $\begin{array}{c}c_{66} \\
(\mathrm{GPa})\end{array}$ & $\begin{array}{c}e_{13} \\
\left(\mathrm{C} / \mathrm{m}^{2}\right)\end{array}$ & $\begin{array}{c}e_{15} \\
\left(\mathrm{C} / \mathrm{m}^{2}\right)\end{array}$ & $\begin{array}{c}e_{33} \\
\left(\mathrm{C} / \mathrm{m}^{2}\right)\end{array}$ & $\begin{array}{c}\chi_{11} \\
(\mathrm{~F} / \mathrm{m})\end{array}$ & $\begin{array}{c}\chi_{33} \\
(\mathrm{~F} / \mathrm{m})\end{array}$ & $\begin{array}{c}\rho \\
\left(\mathrm{kg} / \mathrm{m}^{3}\right)\end{array}$ \\
\hline & 386 & 257 & 257 & 386 & 064 & 064 & - & - & - & 0.0797 & 0.0797 & 7500 \\
\hline PZt-5A & 121.0 & 75.4 & 75.2 & 111.0 & 21.1 & 2.28 & -5.4 & 12.3 & 15.8 & 8.11 & 7.35 & 7500 \\
\hline
\end{tabular}
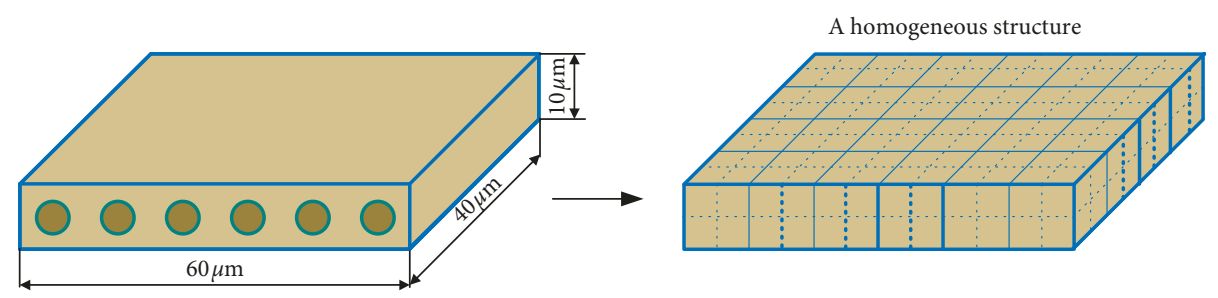

FIgURE 5: A part homogeneous model of the singer-player PCMs strip by AHM.

TABLE 2: The material properties of the singer-player PCMs strip were calculated by AHM.

\begin{tabular}{|c|c|c|c|c|c|c|c|c|c|c|c|}
\hline Volume fraction & $\begin{array}{c}\bar{c}_{11} \\
(\mathrm{GPa})\end{array}$ & $\begin{array}{c}\bar{c}_{12} \\
(\mathrm{GPa})\end{array}$ & $\begin{array}{c}\bar{c}_{13} \\
(\mathrm{GPa})\end{array}$ & $\begin{array}{c}\bar{c}_{33} \\
(\mathrm{GPa})\end{array}$ & $\begin{array}{c}\bar{c}_{44} \\
(\mathrm{GPa})\end{array}$ & $\begin{array}{c}\bar{c}_{66} \\
(\mathrm{GPa})\end{array}$ & $\begin{array}{c}\bar{e}_{15} \\
\left(\mathrm{C} / \mathrm{m}^{2}\right)\end{array}$ & $\begin{array}{c}\bar{e}_{33} \\
\left(\mathrm{C} / \mathrm{m}^{2}\right)\end{array}$ & $\begin{array}{c}\bar{e}_{13} \\
\left(\mathrm{C} / \mathrm{m}^{2}\right)\end{array}$ & $\begin{array}{c}\bar{\chi}_{11} \\
(\mathrm{nF} / \mathrm{m})\end{array}$ & $\begin{array}{c}\bar{\chi}_{33} \\
(\mathrm{nF} / \mathrm{m})\end{array}$ \\
\hline 0.5555 & 9.74292 & 5.54232 & 5.95557 & 35.11748 & 2.17285 & 2.1003 & 0.021904 & 10.879245 & -0.251715 & 0.28018 & 4.27248 \\
\hline
\end{tabular}

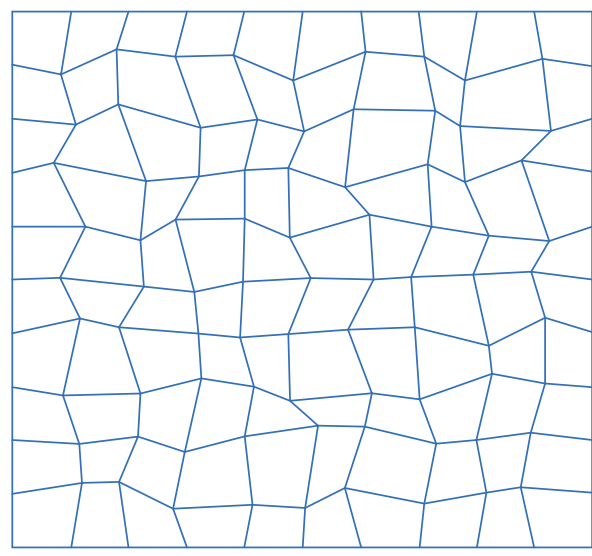

(a)

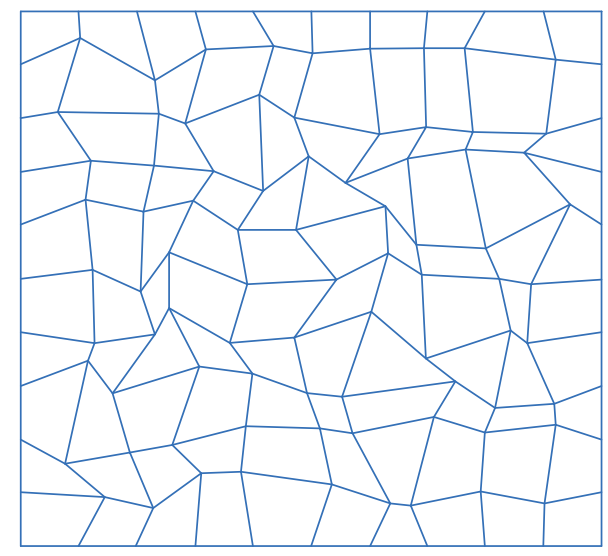

(b)

FIgURE 6: Typical irregular elements with irregularity factor $\alpha_{\mathrm{ir}}=$ (a) 0.3 (I1) and (b) 0.5 (I2).

66.66\%. The relevant boundary condition was $u_{x}=u_{z}=\Phi=0$ at the clamped end.

The 11 effective coefficients estimated by AHM are shown in Table 3. The first 10 natural frequencies of the cantilever PCM beam with $100 \times 10$ uniform elements calculated by CSFEM (Figure 12) agree well with the solutions by FEM using $200 \times 20$ uniform elements. The CSFEM has higher accuracy than FEM. Figure 13 plots the first sixthorder modal shapes, which verify the correctness and validity of CSFEM.

6.3. A Bilayered PCMs Actuator. In this example, the transient responses of a clamp-free bilayered PCM actuator $(L=20 \mathrm{~mm}, b=2 \mathrm{~mm}$, and layer width $=1 \mathrm{~mm}$ ) exposed to triangular-wave load $F$ (time period $T=8 \mathrm{~s}$, and $F_{0}=5 \mathrm{~N}$ ) at point $A$ were investigated (Figures 14 and 15). The actuator consisted of a lower PCM layer and an upper red copper layer, which were supposed to be well bonded. The PCMs (PZT-5A) were buried in the epoxy matrix. A block of 8000 square cells was used in the composite $z$ with the specific fiber volume fraction of $44.44 \%$. The red copper was featured by Young's modulus $(E)=108 \mathrm{GPa}$, Poisson ratio $(\nu)=0.32$, and volume density $(\rho)=8900 \mathrm{~kg} / \mathrm{m}^{3}$ (Table 2). The boundary condition of the actuator was $u_{x}=u_{z}=\Phi=0$ (at the clamped end). The dynamic system equations were addressed by using the implicit integral Newmark scheme. 


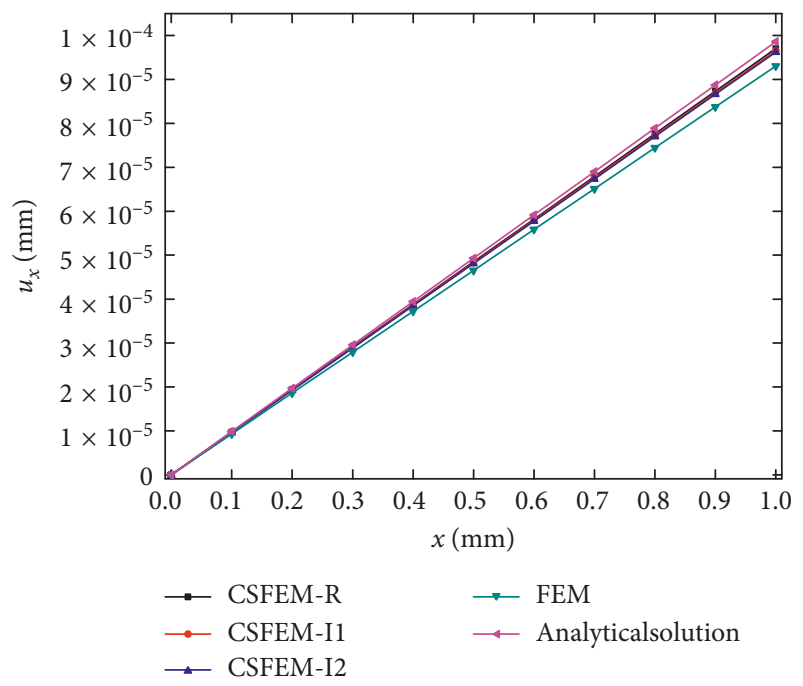

Figure 7: Variation of horizontal displacement $u_{x}$ at the central line $(z=0)$ of the singer-player PCMs strip.

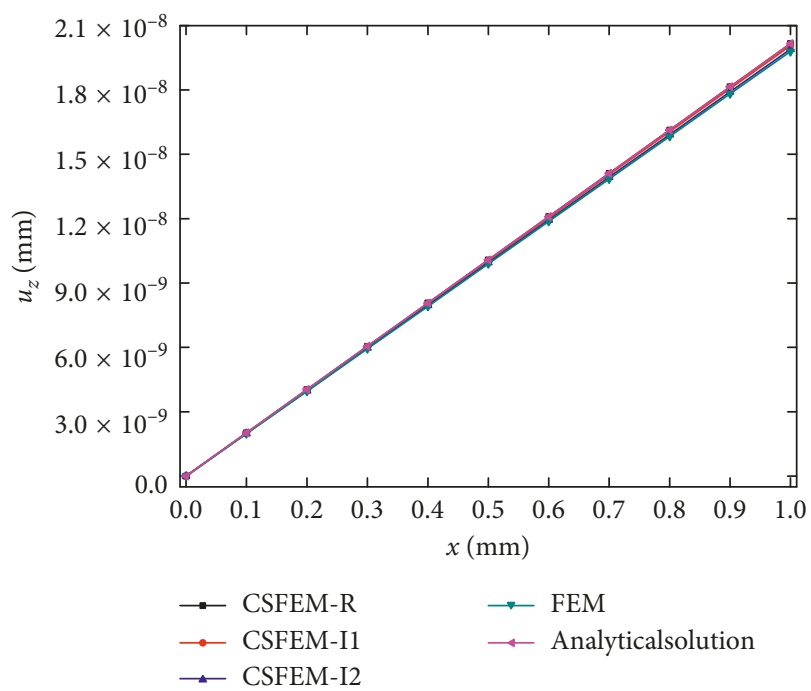

FIGURE 8: Variation of vertical displacement $u_{z}$ at the central line $(z=0)$ of the singer-player PCMs strip.

The 12 effective coefficients calculated using AHM are shown in Table $4(\Delta t=0.002 \mathrm{~s})$. The generalized displacements at points $A$ and $B$ calculated by CSFEM and FEM are shown in Figures 16-21. Clearly, the high agreement of the simulation results confirms the accuracy of CSFEM. CSFEM achieves higher precision by using fewer elements than FEM ( $40 \times 4$ VS $160 \times 16$ meshes). Thus, CSFEM is well feasible for dynamic analysis of PCM structures.

6.4. A PCMs Energy Harvester. The transient responses of a typical PCM energy harvester were investigated at points $A$ and $B$ (Figure 22). The mild steel was featured by $E=210 \mathrm{GPa}, \rho=7800.0 \mathrm{~kg} \cdot \mathrm{m}^{-3}$, and $\nu=0.3$, while red copper by $E=108 \mathrm{GPa}, \rho=8900 \mathrm{~kg} \cdot \mathrm{m}^{-3}$, and $\nu=0.32$ (Table 2). The PCMs (PZT-5A) were embedded in the epoxy matrix. A

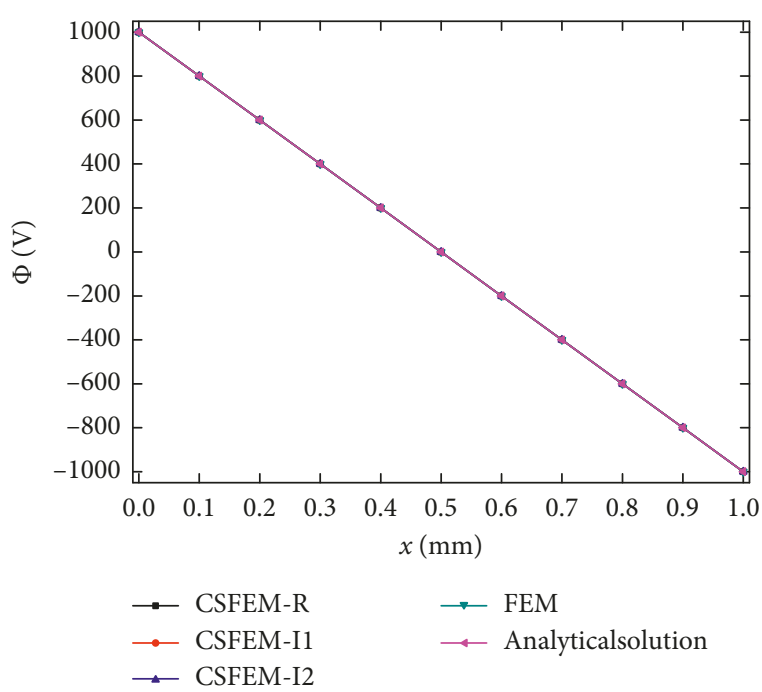

FIgURE 9: Variation of electric potential $\Phi$ at the central line $(z=0)$ of the singer-player PCMs strip.

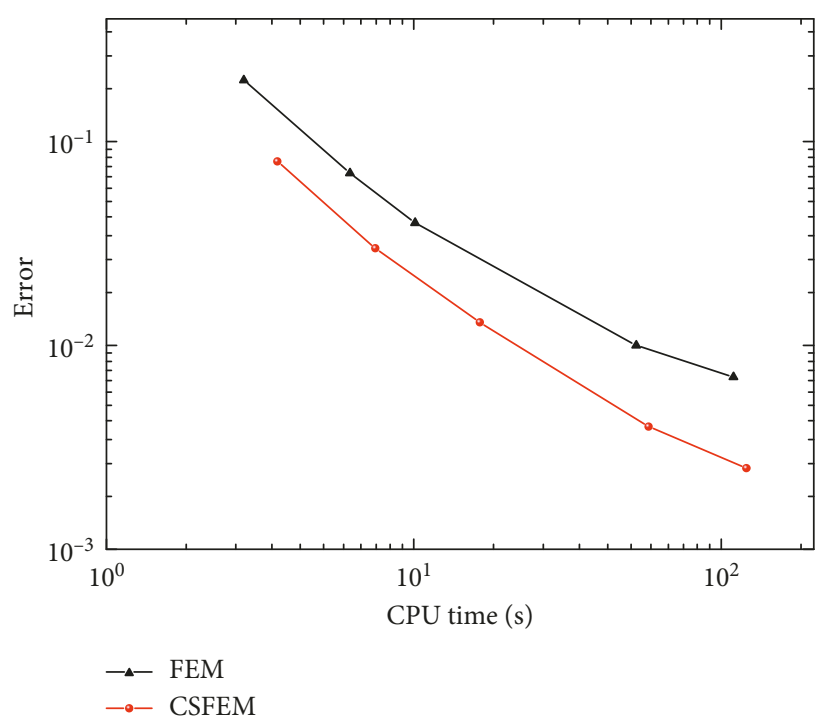

Figure 10: Computational cost by CSFEM and FEM.

block of 8000 square cells was used in the composite $z$ with the specific fiber volume fraction of $55.55 \%$. The boundary and initial conditions were the same as stated above. The sine-wave payload with $8 \mathrm{~s}$ and time step $\Delta t=0.02 \mathrm{~s}$ was applied (Figure 23). The background cells of quadrilateral elements for this harvester were first discretized (Figure 24). The implicit integral Newmark scheme was used to address dynamic system equations.

The 12 effective coefficients calculated using AHM are shown in Table 5. The dynamic responses of the PCM energy harvester were calculated by CSFEM in comparison with FEM (700 VS 5600 quadrilateral elements). The $u_{x}, u_{z}$, and $\Phi$ at points $A$ and $B$ are shown in Figures 25-30. Clearly, the CSFEM produced the generalized displacements closer to real solutions and thereby was proved to 


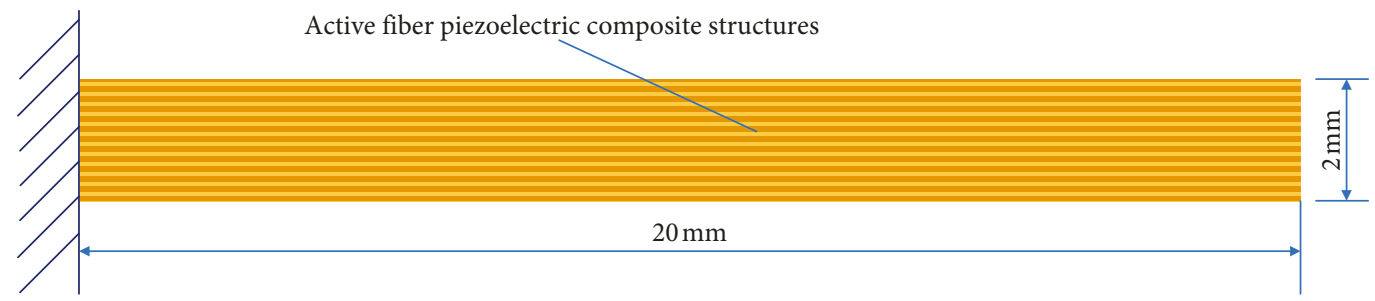

Figure 11: A cantilever PCMs beam.

TABLE 3: The material properties of the cantilever PCMs beam were calculated by AHM.

\begin{tabular}{lccccccccccc}
\hline Volume fraction & $\begin{array}{c}\bar{c}_{11} \\
(\mathrm{GPa})\end{array}$ & $\begin{array}{c}\bar{c}_{12} \\
(\mathrm{GPa})\end{array}$ & $\begin{array}{c}\bar{c}_{13} \\
(\mathrm{GPa})\end{array}$ & $\begin{array}{c}\bar{c}_{33} \\
(\mathrm{GPa})\end{array}$ & $\begin{array}{c}\bar{c}_{44} \\
(\mathrm{GPa})\end{array}$ & $\begin{array}{c}\bar{c}_{66} \\
(\mathrm{GPa})\end{array}$ & $\begin{array}{c}\bar{e}_{15} \\
\left(\mathrm{C} / \mathrm{m}^{2}\right)\end{array}$ & $\begin{array}{c}\bar{e}_{33} \\
\left(\mathrm{C} / \mathrm{m}^{2}\right)\end{array}$ & $\begin{array}{c}\bar{e}_{13} \\
\left(\mathrm{C} / \mathrm{m}^{2}\right)\end{array}$ & $\begin{array}{c}\bar{\chi}_{11} \\
(\mathrm{nF} / \mathrm{m})\end{array}$ & $\begin{array}{c}\bar{\chi}_{33} \\
(\mathrm{nF} / \mathrm{m})\end{array}$ \\
\hline 0.6666 & 13.27801 & 7.01985 & 7.87201 & 42.31662 & 3.18867 & $\begin{array}{c}\rho \\
\left(\mathrm{kg} / \mathrm{m}^{3}\right)\end{array}$ \\
\hline
\end{tabular}

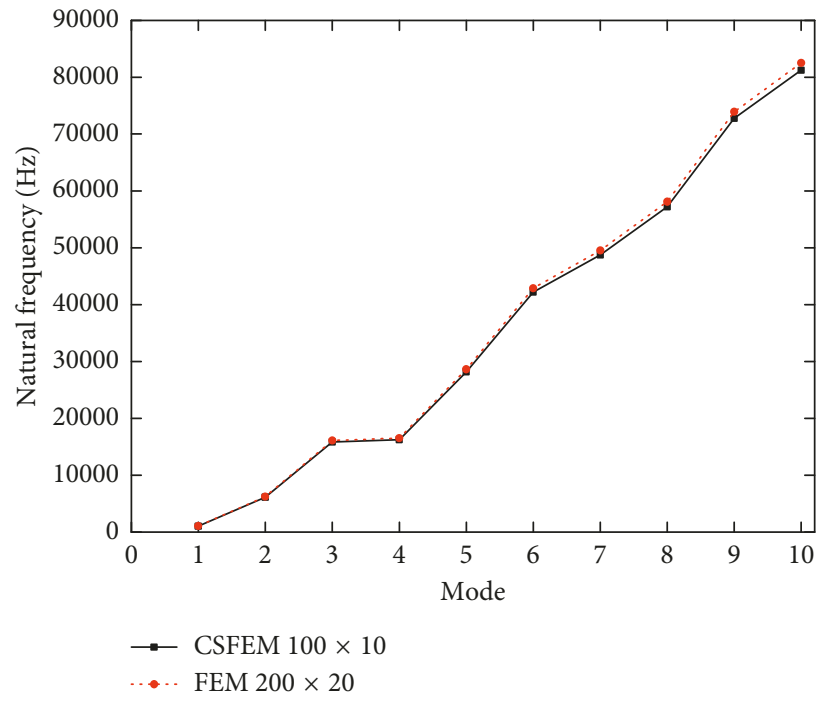

FIGURE 12: First 10 natural frequencies of the cantilever PCMs beam using CSFEM and FEM.

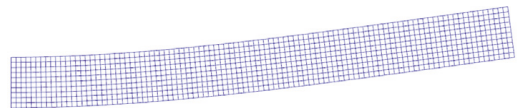

(a)

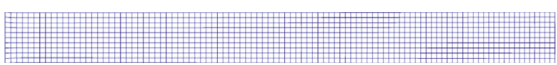

(d)

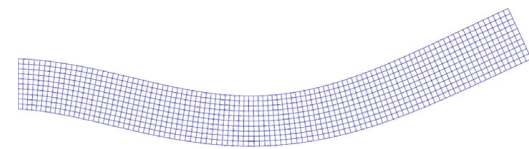

(b)

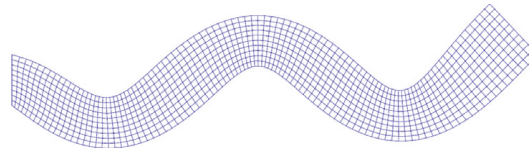

(e)

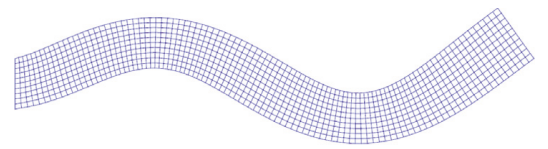

(c)

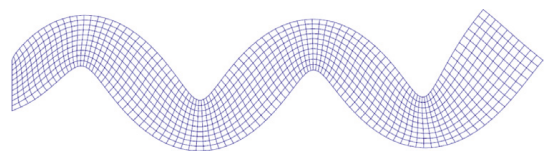

(f)

FIGURE 13: First 6 mode shapes of the cantilever PCMs beam by CSFEM and FEM. (a) Mode shape 1. (b) Mode shape 2. (c) Mode shape 3. (d) Mode shape 4. (e) Mode shape 5. (f) Mode shape 6.

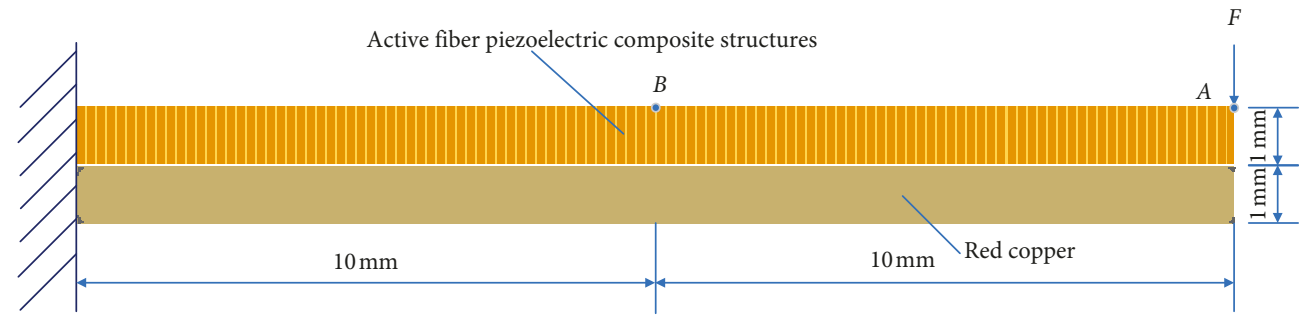

FIgURE 14: Geometry of the bilayered PCMs actuator. 


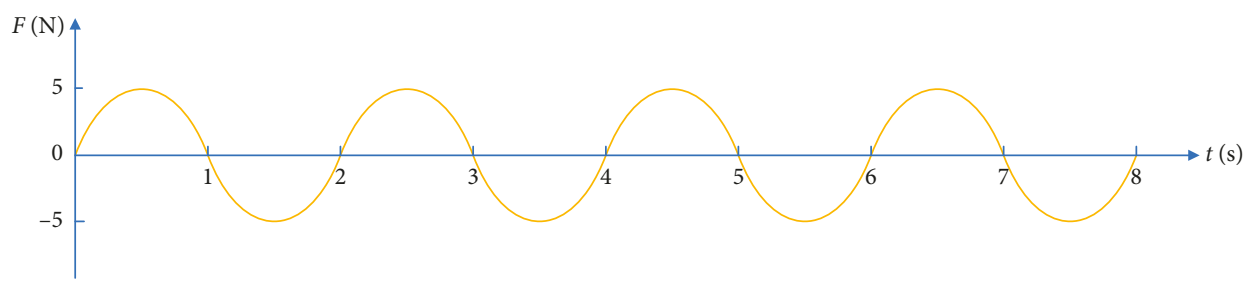

FIgURE 15: Sine-wave load at point $A$.

TABLE 4: The material properties of the bilayered PCMs actuator were calculated by AHM.

\begin{tabular}{|c|c|c|c|c|c|c|c|c|c|c|c|c|}
\hline Volume fraction & $\begin{array}{c}\bar{c}_{11} \\
(\mathrm{GPa})\end{array}$ & $\begin{array}{c}\bar{c}_{12} \\
(\mathrm{GPa})\end{array}$ & $\begin{array}{c}\bar{c}_{13} \\
(\mathrm{GPa})\end{array}$ & $\begin{array}{c}\bar{c}_{33} \\
(\mathrm{GPa})\end{array}$ & $\begin{array}{c}\bar{c}_{44} \\
(\mathrm{GPa})\end{array}$ & $\begin{array}{c}\bar{c}_{66} \\
(\mathrm{GPa})\end{array}$ & $\begin{array}{c}\bar{e}_{15} \\
\left(\mathrm{C} / \mathrm{m}^{2}\right)\end{array}$ & $\begin{array}{c}\bar{e}_{33} \\
\left(\mathrm{C} / \mathrm{m}^{2}\right)\end{array}$ & $\begin{array}{c}\bar{e}_{13} \\
\left(\mathrm{C} / \mathrm{m}^{2}\right)\end{array}$ & $\begin{array}{c}\bar{\chi}_{11} \\
(\mathrm{nF} / \mathrm{m})\end{array}$ & $\begin{array}{c}\bar{\chi}_{33} \\
(\mathrm{nF} / \mathrm{m})\end{array}$ & $\begin{array}{c}\rho \\
\left(\mathrm{kg} / \mathrm{m}^{3}\right)\end{array}$ \\
\hline 0.4444 & 7.61822 & 4.56846 & 4.77091 & 28.4779 & 1.61506 & 1.52487 & 0.010859 & 8.73225 & -0.16364 & 0.20584 & 3.43606 & 7500 \\
\hline
\end{tabular}

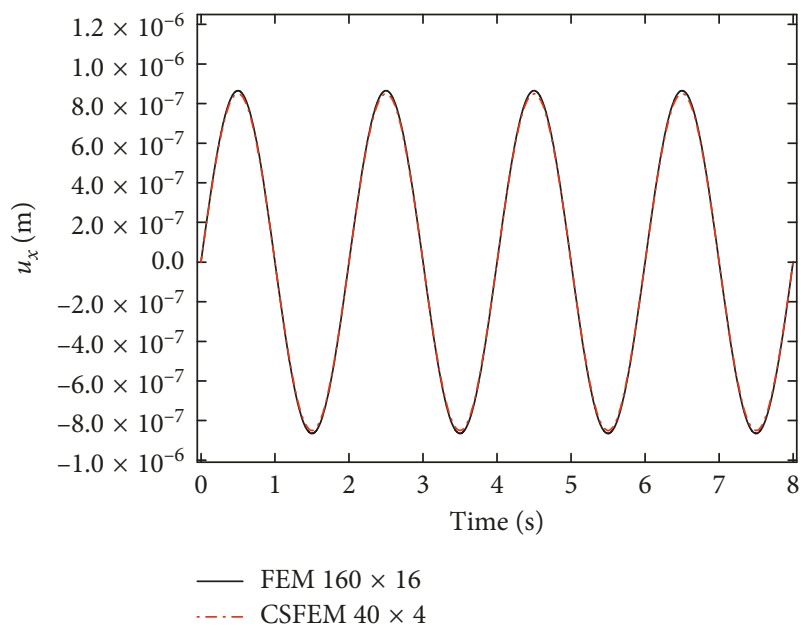

Figure 16: The variation of the displacement $u_{x}$ at point $A$ with respect to time.

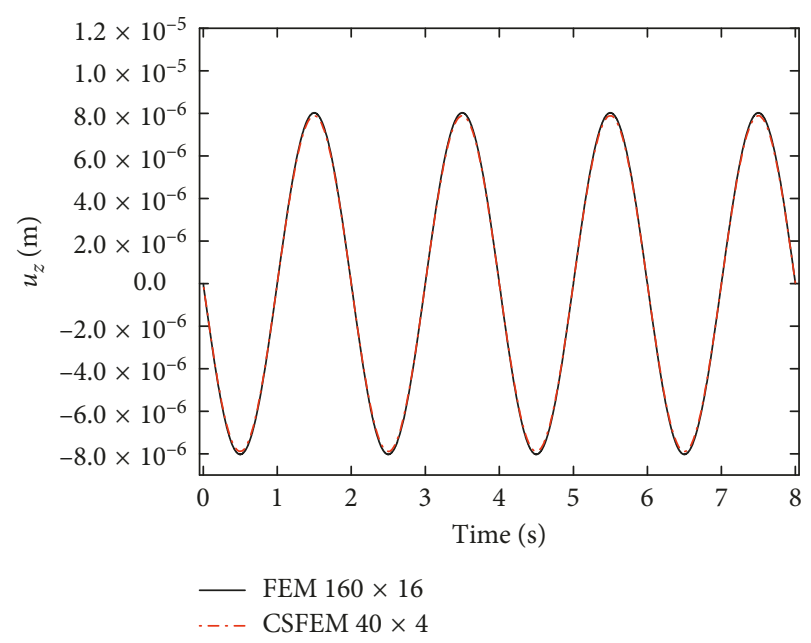

Figure 17: The variation of the displacement $u_{z}$ at point $A$ with respect to time.

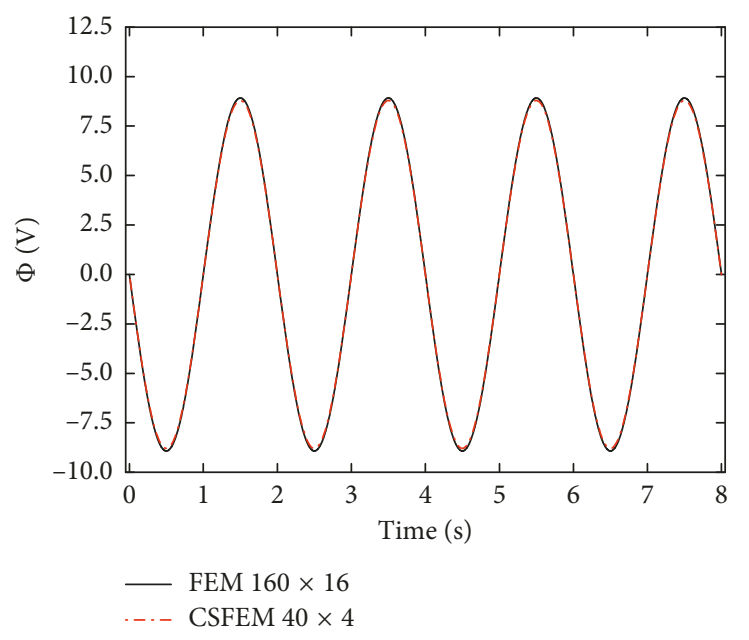

Figure 18: The variation of the electrical potential $\Phi$ at point $A$ with respect to time.

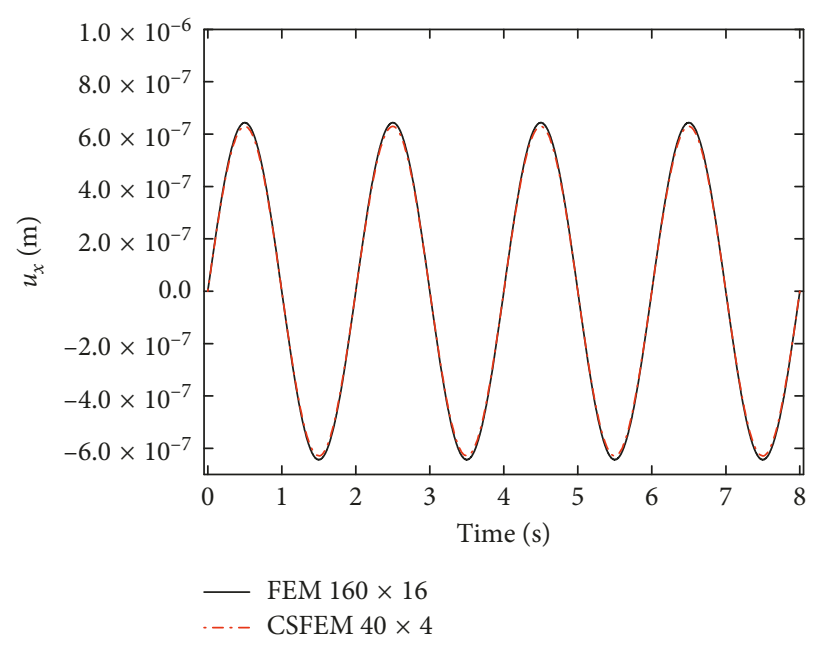

FIgUre 19: The variation of the displacement $u_{x}$ at point $B$ with respect to time. 


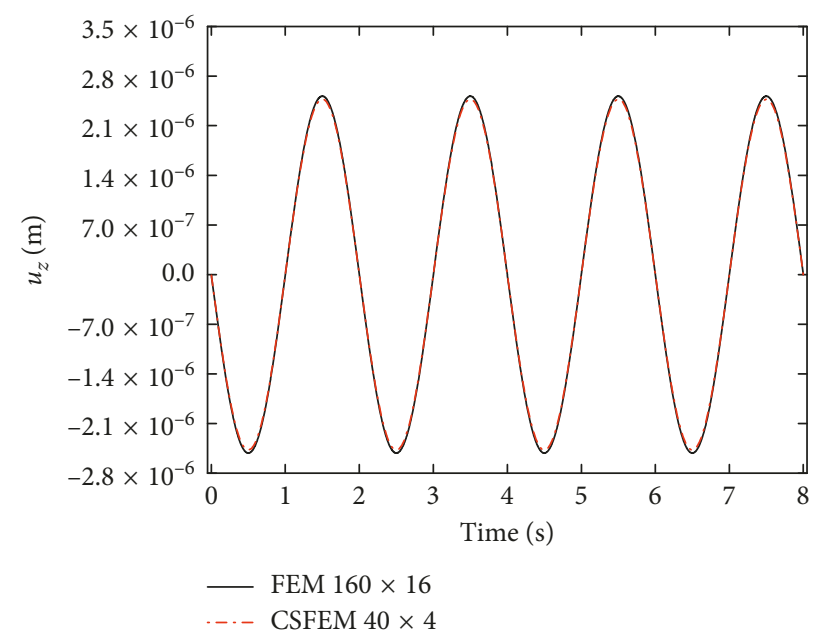

FIgURE 20: The variation of the displacement $u_{z}$ at point $A$ with respect to time.

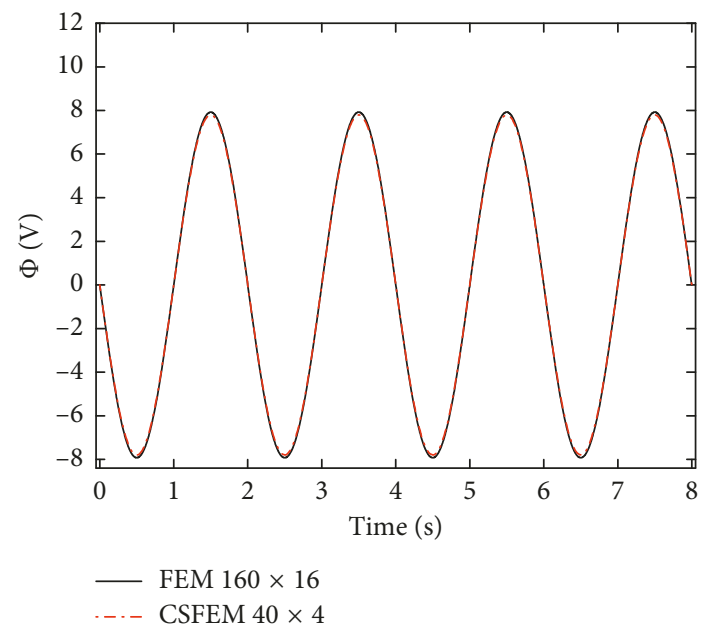

Figure 21: The variation of the electrical potential $\Phi$ at point $A$ with respect to time.

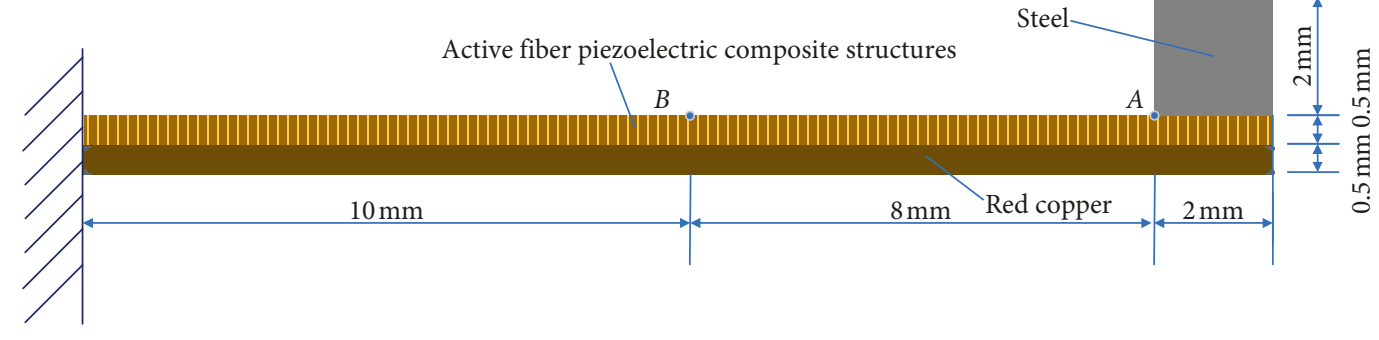

FIgURE 22: Geometry of PCMs energy harvester.

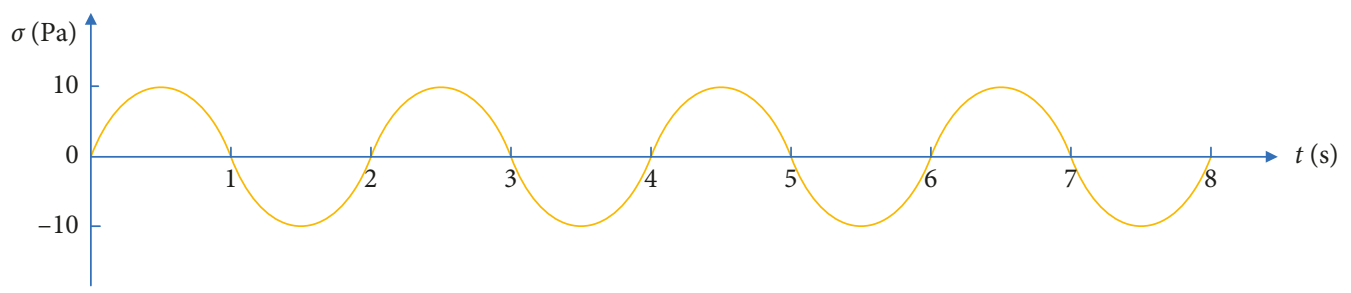

FIGURE 23: Sine-wave load at top surface of steel. 


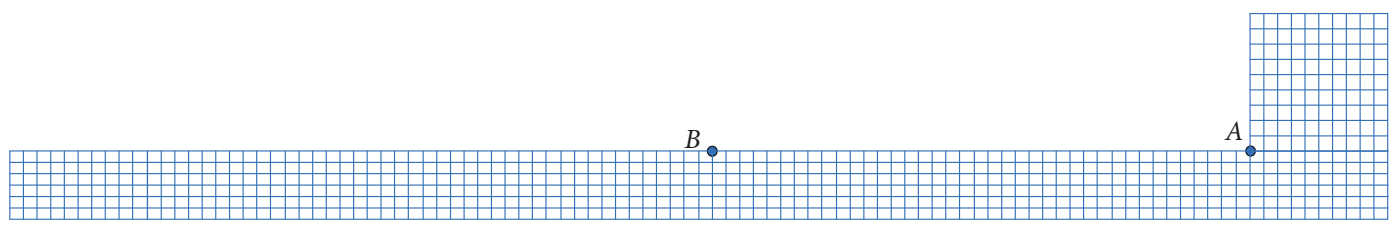

(a)

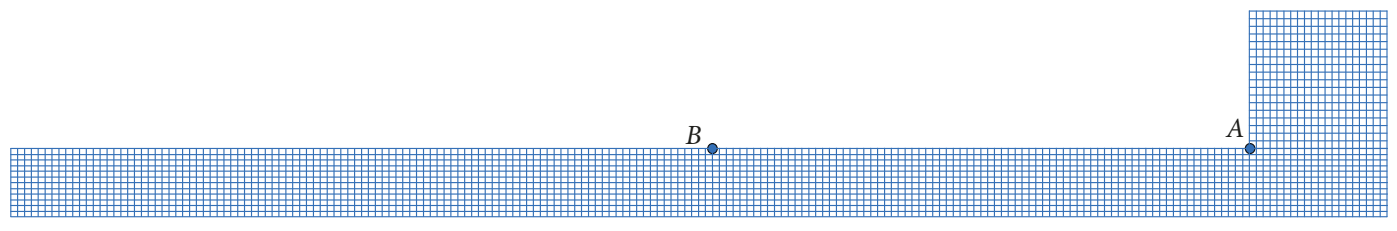

(b)

Figure 24: Discrete meshes of PCMs energy harvester. (a) Elements of CSFEM. (b) Elements of FEM.

TABle 5: The material properties of the PCMs energy harvester were calculated using AHM.

\begin{tabular}{|c|c|c|c|c|c|c|c|c|c|c|c|}
\hline Volume fraction & $\begin{array}{c}\bar{c}_{11} \\
(\mathrm{GPa})\end{array}$ & $\begin{array}{c}\bar{c}_{12} \\
(\mathrm{GPa})\end{array}$ & $\begin{array}{c}\bar{c}_{13} \\
(\mathrm{GPa})\end{array}$ & $\begin{array}{c}\bar{c}_{33} \\
(\mathrm{GPa})\end{array}$ & $\begin{array}{c}\bar{c}_{44} \\
(\mathrm{GPa})\end{array}$ & $\begin{array}{c}\bar{c}_{66} \\
(\mathrm{GPa})\end{array}$ & $\begin{array}{c}\bar{e}_{15} \\
\left(\mathrm{C} / \mathrm{m}^{2}\right)\end{array}$ & $\begin{array}{c}\bar{e}_{33} \\
\left(\mathrm{C} / \mathrm{m}^{2}\right)\end{array}$ & $\begin{array}{c}\bar{e}_{13} \\
\left(\mathrm{C} / \mathrm{m}^{2}\right)\end{array}$ & $\begin{array}{c}\bar{\chi}_{11} \\
(\mathrm{nF} / \mathrm{m})\end{array}$ & $\begin{array}{c}\bar{\chi}_{33} \\
(\mathrm{nF} / \mathrm{m})\end{array}$ \\
\hline 0.5555 & 9.74292 & 5.54232 & 5.95557 & 35.11748 & 2.17285 & 2.1003 & 0.021904 & 10.879245 & -0.251715 & 0.28018 & 4.27248 \\
\hline
\end{tabular}

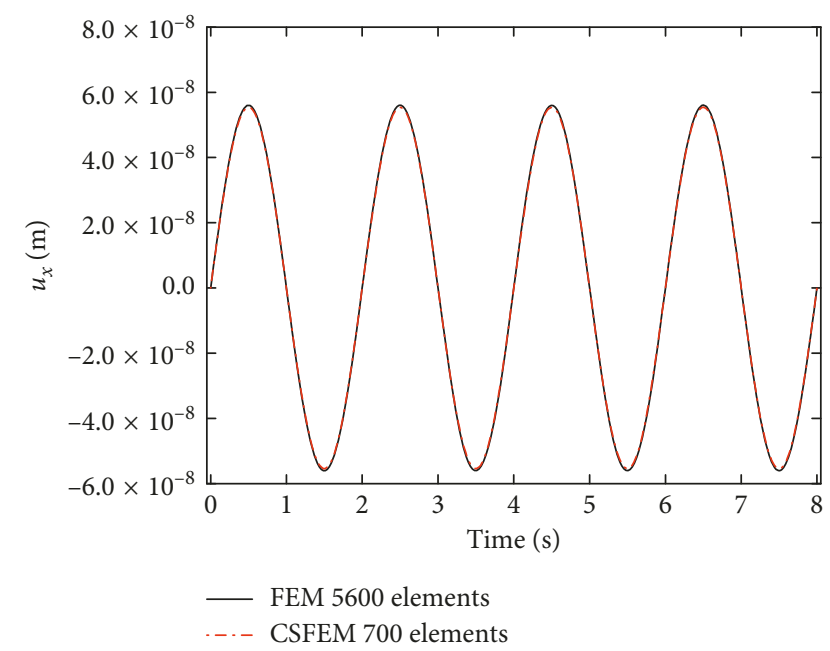

Figure 25: The variation of the displacement $u_{x}$ of the PCMs energy harvester at point $A$ with respect to time.

reduce the number of meshes and return more-accurate results.

\section{Conclusions}

The dynamic responses of PCM structures were investigated. Firstly, the effective properties of PCMs were calculated by AHM. Secondly, the effective CSFEM was established by applying gradient smoothing to calculate the electromechanical coupling field of FEM. Then, the equations for dynamic response computation over the multiphysics coupling field of PCMs were derived. Finally, a bilayered

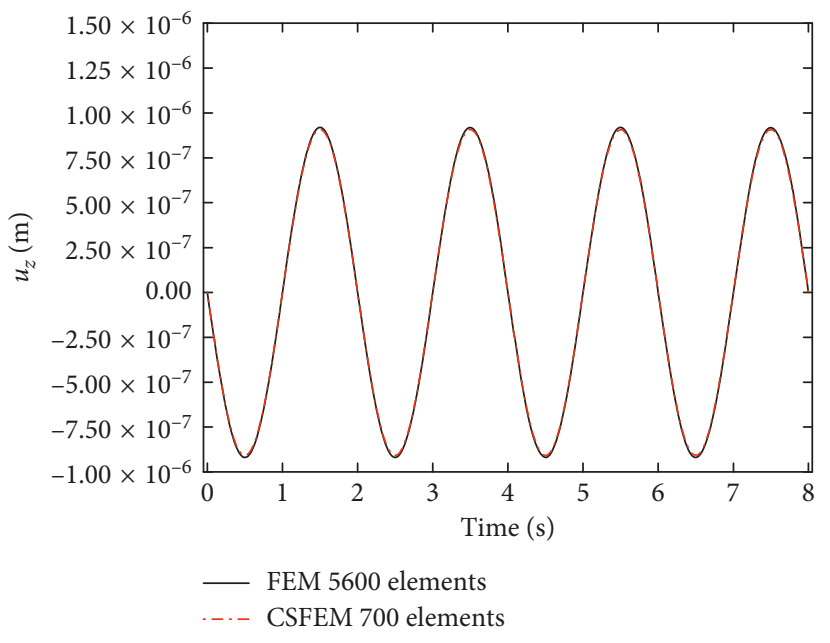

FIgURE 26: The variation of the displacement $u_{z}$ of the PCMs energy harvester at point $A$ with respect to time.

PCM actuator and a PCM energy harvester were calculated by both CSFEM and FEM.

(i) CSFEM reduced the systematic stiffness of FEM and thereby enhanced the accuracy under the same element number. CSFEM took less computation time than FEM under the same accuracy.

(ii) CSFEM avoided the derivation of shape functions and reduced the requirement of form function continuity by simply converting area integral to boundary integral in the solution domain.

(iii) The practical bilayered PCM actuator and the PCM energy harvester were modeled by CSFEM, 


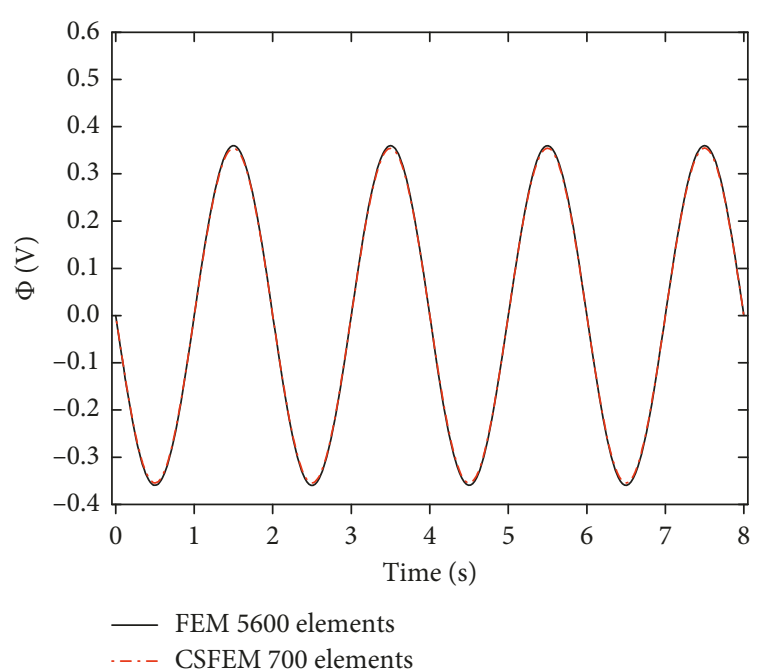

FIgUre 27: The variation of the electrical potential $\Phi$ of the PCMs energy harvester at point $A$ with respect to time.

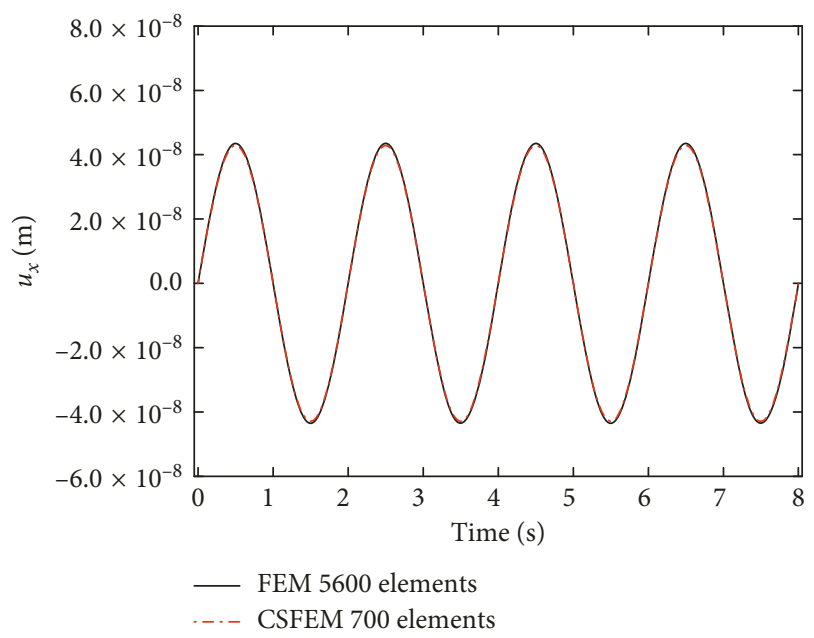

Figure 28: The variation of the displacement $u_{x}$ of the PCMs energy harvester at point $B$ with respect to time.

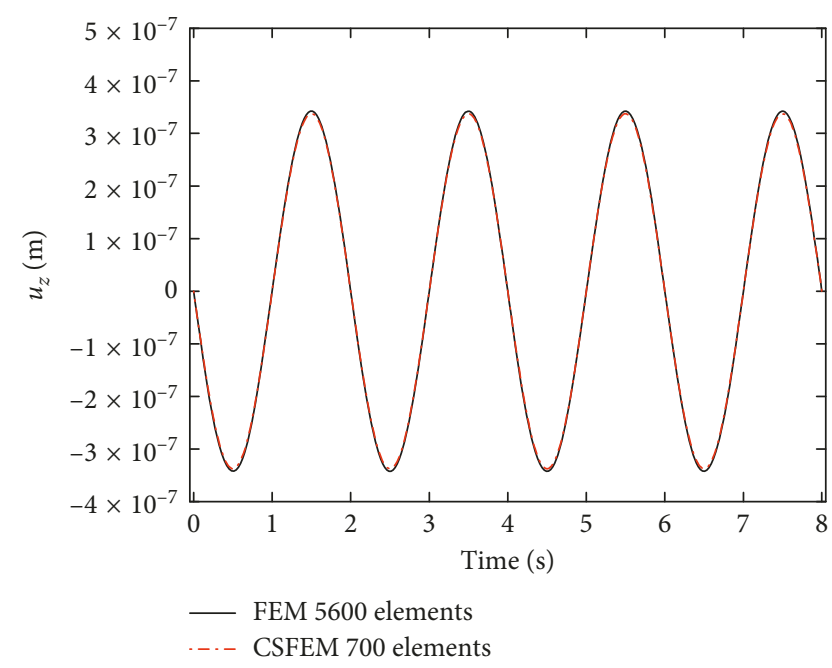

Figure 29: The variation of the displacement $u_{z}$ of the PCMs energy harvester at point $B$ with respect to time.

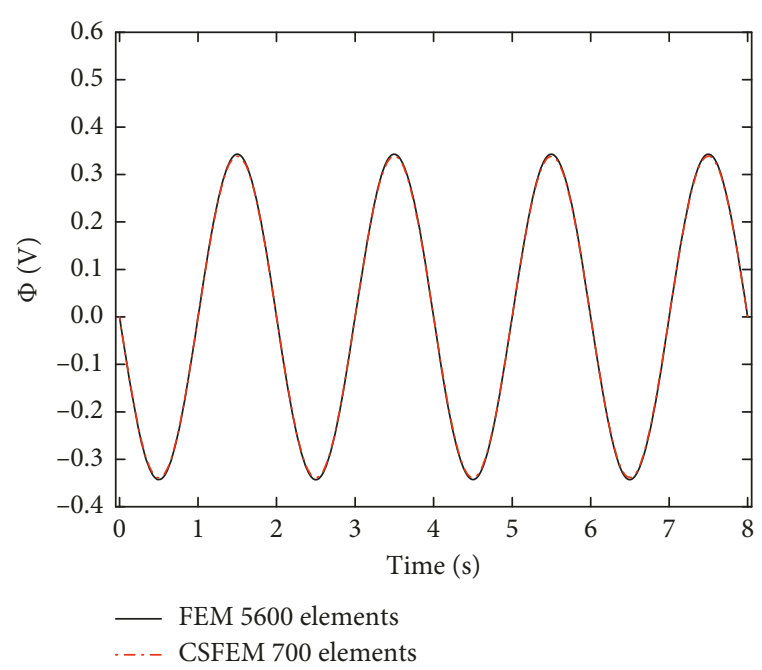

Figure 30: The variation of the electrical potential $\Phi$ of the PCMs energy harvester at point $B$ with respect to time.

which outperformed FEM in calculating the transient responses by reducing the number of meshes.

\section{Data Availability}

The data used to support the findings of this study are included within the article.

\section{Conflicts of Interest}

The authors declare that they have no conflicts of interest.

\section{Acknowledgments}

This work was supported by the National Key R\&D Program of China (grant no. 2018YFF01012401-06), Foundation Sciences Jilin Provincial (grant no. 20170101043JC), Educational Commission of Jilin Province of China (grant nos. JJKH20180084KJ and JJKH20190131KJ), Graduate Innovation Fund of Jilin University (grant no. 101832018C184), and the Fundamental Research Funds for the Central Universities.

\section{References}

[1] X.-Q. Fang, J.-X. Liu, and V. Gupta, "Fundamental formulations and recent achievements in piezoelectric nanostructures: a review," Nanoscale, vol. 5, no. 5, pp. 17161726, 2013.

[2] P. Tan and L. Tong, "Micro-electromechanics models for piezoelectric-fiber-reinforced composite materials," Composites Science and Technology, vol. 61, no. 5, pp. 759-769, 2001.

[3] X. Wang, J. Zhou, J. Song, J. Liu, N. Xu, and Z. L. Wang, "Piezoelectric field effect transistor and nanoforce sensor based on a single $\mathrm{ZnO}$ nanowire," Nano Letters, vol. 6, no. 12, pp. 2768-2772, 2006.

[4] M. S. Azzouz, C. Mei, J. S. Bevan, and J. J. Ro, "Finite element modeling of MFC/AFC actuators and performance of MFC," 
Journal of Intelligent Material Systems and Structures, vol. 12, no. 9, pp. 601-612, 2001.

[5] Y. Qin, X. Wang, and Z. L. Wang, "Microfibre-nanowire hybrid structure for energy scavenging," Nature, vol. 451, no. 7180 , pp. 809-813, 2008.

[6] C. Gui, J. Bai, and W. Zuo, "Simplified crashworthiness method of automotive frame for conceptual design," Thinwalled Structures, vol. 131, pp. 324-335, 2018.

[7] H. L. W. Chan and J. Unsworth, "Simple model for piezoelectric ceramic/polymer 1-3 composites used in ultrasonic transducer applications," IEEE Transactions on Ultrasonics, Ferroelectrics and Frequency Control, vol. 36, no. 4, pp. 434441, 1989.

[8] W. A. Smith and B. A. Auld, "Modeling 1-3 composite piezoelectrics: thickness-mode oscillations," IEEE Transactions on Ultrasonics, Ferroelectrics and Frequency Control, vol. 38, no. 1, pp. 40-47, 1991.

[9] B. Wang, "Three-dimensional analysis of a flat elliptical crack in a piezoelectric material," International Journal of Engineering Science, vol. 30, no. 6, pp. 781-791, 1992.

[10] M. L. Dunn and M. Taya, "Micromechanics predictions of the effective electroelastic moduli of piezoelectric composites," International Journal of Solids and Structures, vol. 30, no. 2, pp. 161-175, 1993.

[11] T. Chen, "Piezoelectric properties of multiphase fibrous composites: some theoretical results," Journal of the Mechanics and Physics of Solids, vol. 41, no. 11, pp. 1781-1794, 1993.

[12] A. Benjeddou, "Advances in piezoelectric finite element modeling of adaptive structural elements: a survey," Computers \& Structures, vol. 76, no. 1-3, pp. 347-363, 2000.

[13] Y. Benveniste and G. J. Dvorak, "Uniform fields and universal relations in piezoelectric composites," Journal of the Mechanics and Physics of Solids, vol. 40, no. 6, pp. 1295-1312, 1992.

[14] R. Rodríguez-Ramos, F. J. Sabina, R. Guinovart-Díraz, and J. Bravo-Castillero, "Closed-form expressions for the effective coefficients of a fiber-reinforced composite with transversely isotropic constituents-I. Elastic and square symmetry," Mechanics of Materials, vol. 33, no. 4, pp. 223-235, 2001.

[15] J. Bravo-Castillero, R. Guinovart-Díaz, F. J. Sabina, and R. Rodríguez-Ramos, "Closed-form expressions for the effective coefficients of a fiber-reinforced composite with transversely isotropic constituents-II. Piezoelectric and square symmetry," Mechanics of Materials, vol. 33, no. 4, pp. 237-248, 2001.

[16] R. Guinovart-Díaz, J. Bravo-Castillero, R. Rodríguez-Ramos, R. Martínez-Rosado, F. Serranía, and M. Navarrete, "Modeling of elastic transversely isotropic composite using the asymptotic homogenization method. Some comparisons with other models," Materials Letters, vol. 56, no. 6, pp. 889-894, 2002.

[17] I. Sevostianov and M. Kachanov, "Plasma-sprayed ceramic coatings: anisotropic elastic and conductive properties in relation to the microstructure; cross-property correlations," Materials Science and Engineering: A, vol. 297, no. 1-2, pp. 235-243, 2001.

[18] I. V. Andrianov, V. V. Danishevs'kyy, and D. Weichert, "Asymptotic determination of effective elastic properties of composite materials with fibrous square-shaped inclusions," European Journal of Mechanics-A/Solids, vol. 21, no. 6, pp. 1019-1036, 2002.

[19] J. A. Otero, J. Bravo-Castillero, R. Guinovart-Díaz, R. Rodríguez-Ramos, and G. A. Maugin, "Analytical expressions of effective constants for a piezoelectric composite reinforced with square cross-section fibers," Archives of Mechanics, vol. 55, no. 4, pp. 357-371, 2003.

[20] R. de Medeiros, R. Rodríguez-Ramos, R. Guinovart-Díaz, J. Bravo-Castillero, J. A. Otero, and V. Tita, "Numerical and analytical analyses for active fiber composite piezoelectric composite materials," Journal of Intelligent Material Systems and Structures, vol. 26, no. 1, pp. 101-118, 2014.

[21] J. M. Viaño, C. Ribeiro, J. Figueiredo, and Á. Rodríguez-Arós, "A high order model for piezoelectric rods: an asymptotic approach," International Journal of Solids and Structures, vol. 81, pp. 294-310, 2016.

[22] K. C. Le, "An asymptotically exact theory of functionally graded piezoelectric shells," International Journal of Engineering Science, vol. 112, pp. 42-62, 2017.

[23] F. Fantoni, A. Bacigalupo, and M. Paggi, "Multi-field asymptotic homogenization of thermo-piezoelectric materials with periodic microstructure," International Journal of Solids and Structures, vol. 120, pp. 31-56, 2017.

[24] R. Kar-Gupta and T. A. Venkatesh, "Electromechanical response of 1-3 piezoelectric composites: a numerical model to assess the effects of fiber distribution," Acta Materialia, vol. 55, no. 4, pp. 1275-1292, 2007.

[25] K.-K. Jin, H. Yuanchen Huang, Y.-H. Lee, and H. Sung Kyu $\mathrm{Ha}$, "Distribution of micro stresses and interfacial tractions in unidirectional composites," Journal of Composite Materials, vol. 42, no. 18, pp. 1825-1849, 2008.

[26] M. Würkner, H. Berger, and U. Gabbert, "On numerical evaluation of effective material properties for composite structures with rhombic fiber arrangements," International Journal of Engineering Science, vol. 49, no. 4, pp. 322-332, 2011.

[27] N. Mishra, B. Krishna, R. Singh, and K. Das, "Evaluation of effective elastic, piezoelectric, and dielectric properties of SU8/ZnO nanocomposite for vertically integrated nanogenerators using finite element method," Journal of Nanomaterials, vol. 2017, Article ID 1924651, 14 pages, 2017.

[28] C. R. Bowen, V. Y. Topolov, Y. Zhang, and A. A. Panich, "1-3type composites based on ferroelectrics: electromechanical coupling, figures of merit, and piezotechnical energyharvesting applications," Energy Technology, vol. 6, no. 5, pp. 813-814, 2018.

[29] A. A. Cannarozzi and F. Ubertini, "Some hybrid variational methods for linear electroelasticity problems," International Journal of Solids and Structures, vol. 38, no. 15, pp. 2573-2596, 2001.

[30] K. Y. Sze and Y. S. Pan, "Hybrid finite element models for piezoelectric materials," Journal of Sound and Vibration, vol. 226, no. 3, pp. 519-547, 1999.

[31] K. Y. Sze and L. Q. Yao, "Modelling smart structures with segmented piezoelectric sensors and actuators," Journal of Sound and Vibration, vol. 235, no. 3, pp. 495-520, 2000.

[32] K. Y. Sze, X.-M. Yang, and L.-Q. Yao, "Stabilized plane and axisymmetric piezoelectric finite element models," Finite Elements in Analysis and Design, vol. 40, no. 9-10, pp. 1105-1122, 2004.

[33] C. S. Long, P. W. Loveday, and A. A. Groenwold, "Planar four node piezoelectric elements with drilling degrees of freedom," International Journal for Numerical Methods in Engineering, vol. 65, no. 11, pp. 1802-1830, 2006.

[34] C. W. Lim and C. W. H. Lau, "A new two-dimensional model for electro-mechanical response of thick laminated piezoelectric actuator," International Journal of Solids and Structures, vol. 42, no. 20, pp. 5589-5611, 2005.

[35] R. Zemčík, R. Rolfes, M. Rose, and J. Teßmer, "Highperformance four-node shell element with piezoelectric 
coupling for the analysis of smart laminated structures," International Journal for Numerical Methods in Engineering, vol. 70, no. 8, pp. 934-961, 2007.

[36] M. Jaroslav, "Smart materials and structures-a finite element approach-an addendum: a bibliography (1997-2002)," Modelling and Simulation in Materials Science and Engineering, vol. 11, no. 5, pp. 707-704, 2003.

[37] E. Carrera and M. Boscolo, "Classical and mixed finite elements for static and dynamic analysis of piezoelectric plates," International Journal for Numerical Methods in Engineering, vol. 70, no. 10, pp. 1135-1181, 2007.

[38] X. Y. Cui, G. Wang, and G. Y. Li, "A nodal integration axisymmetric thin shell model using linear interpolation," Applied Mathematical Modelling, vol. 40, pp. 2720-2742, 2016.

[39] X. Y. Cui, X. Hu, G. Wang, and G. Y. Li, "An accurate and efficient scheme for acoustic-structure interaction problems based on unstructured mesh," Computer Methods in Applied Mechanics and Engineering, vol. 317, pp. 1122-1145, 2017.

[40] Y. H. Bie, X. Y. Cui, and Z. C. Li, "A coupling approach of state-based peridynamics with node-based smoothed finite element method," Computer Methods in Applied Mechanics and Engineering, vol. 331, pp. 675-700, 2018.

[41] L. Zhou, S. Ren, G. Meng, X. Li, and F. Cheng, "A multiphysics node-based smoothed radial point interpolation method for transient responses of magneto-electro-elastic structures," Engineering Analysis with Boundary Elements, vol. 101, pp. 371-384, 2019.

[42] L. Zhou, B. Nie, S. Ren, R. Liu, X. Li, and B. Xue, "Coupling magneto-electro-elastic cell-based smoothed radial point interpolation method for static and dynamic characterization of MEE structures," Acta Mechanica, vol. 230, no. 5, pp. 1641-1662, 2019.

[43] X. Hu, X. Y. Cui, Q. Y. Zhang, G. Wang, and G. Y. Li, “The stable node-based smoothed finite element method for analyzing acoustic radiation problems," Engineering Analysis with Boundary Elements, vol. 80, pp. 142-152, 2017.

[44] P. Phung-Van, T. Nguyen-Thoi, T. Le-Dinh, and H. NguyenXuan, "Static and free vibration analyses and dynamic control of composite plates integrated with piezoelectric sensors and actuators by the cell-based smoothed discrete shear gap method (CS-FEM-DSG3)," Smart Materials and Structures, vol. 22, no. 9, article 095026, 2013.

[45] W. Zeng and G. R. Liu, "Smoothed finite element methods (SFEM): an overview and recent developments," Archives of Computational Methods in Engineering, vol. 25, no. 2, pp. 397-435, 2018.

[46] J. Yue, G.-R. Liu, M. Li, and R. Niu, "A cell-based smoothed finite element method for multi-body contact analysis using linear complementarity formulation," International Journal of Solids and Structures, vol. 141-142, pp. 110-126, 2018.

[47] X. B. Hu, X. Y. Cui, Z. M. Liang, and G. Y. Li, "The performance prediction and optimization of the fiber-reinforced composite structure with uncertain parameters," Composite Structures, vol. 164, pp. 207-218, 2017.

[48] L. Zhou, M. Li, G. Meng, and H. Zhao, "An effective cell-based smoothed finite element model for the transient responses of magneto-electro-elastic structures," Journal of Intelligent Material Systems and Structures, vol. 29, no. 14, pp. 30063022, 2018.

[49] L. M. Zhou, G. W. Meng, F. Li, and H. Wang, "Cell-based smoothed finite element method-virtual crack closure technique for a piezoelectric material of crack," Mathematical
Problems in Engineering, vol. 2015, Article ID 371083, 10 pages, 2015.

[50] L. Zhou, S. Ren, C. Liu, and Z. Ma, "A valid inhomogeneous cell-based smoothed finite element model for the transient characteristics of functionally graded magneto-electro-elastic structures," Composite Structures, vol. 208, pp. 298-313, 2019.

[51] L. Zhou, M. Li, Z. Ma et al., "Steady-state characteristics of the coupled magneto-electro-thermo-elastic multi-physical system based on cell-based smoothed finite element method," Composite Structures, vol. 219, pp. 111-128, 2019.

[52] X. Y. Cui, X. B. Hu, and Y. Zeng, "A copula-based perturbation stochastic method for fiber-reinforced composite structures with correlations," Computer Methods in Applied Mechanics and Engineering, vol. 322, pp. 351-372, 2017.

[53] E. Li, Z. C. He, L. Chen, B. Li, X. Xu, and G. R. Liu, "An ultraaccurate hybrid smoothed finite element method for piezoelectric problem," Engineering Analysis with Boundary Elements, vol. 50, pp. 188-197, 2015.

[54] H. Nguyen-Xuan, G. R. Liu, T. Nguyen-Thoi, and C. NguyenTran, "An edge-based smoothed finite element method for analysis of two-dimensional piezoelectric structures," Smart Materials and Structures, vol. 18, no. 6, article 065015, 2009.

[55] T. Vo-Duy, T. Truong-Thi, V. Ho-Huu, and T. Nguyen-Thoi, "Frequency optimization of laminated functionally graded carbon nanotube reinforced composite quadrilateral plates using smoothed FEM and evolution algorithm," Journal of Composite Materials, vol. 52, no. 14, pp. 1971-1986, 2018.

[56] S. Bhowmick and G. R. Liu, "A phase-field modeling for brittle fracture and crack propagation based on the cell-based smoothed finite element method," Engineering Fracture Mechanics, vol. 204, pp. 369-387, 2018.

[57] A. L. N. Pramod, S. Natarajan, A. J. M. Ferreira, E. Carrera, and M. Cinefra, "Static and free vibration analysis of cross-ply laminated plates using the Reissner-mixed variational theorem and the cell based smoothed finite element method," European Journal of Mechanics-A/Solids, vol. 62, pp. 14-21, 2017.

[58] R. R. Ohs and N. R. Aluru, "Meshless analysis of piezoelectric devices," Computational Mechanics, vol. 27, no. 1, pp. 23-36, 2001. 


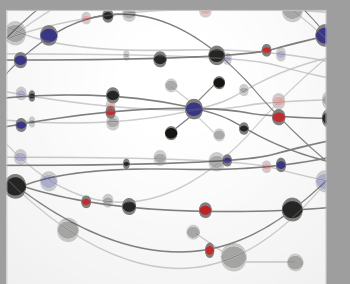

The Scientific World Journal
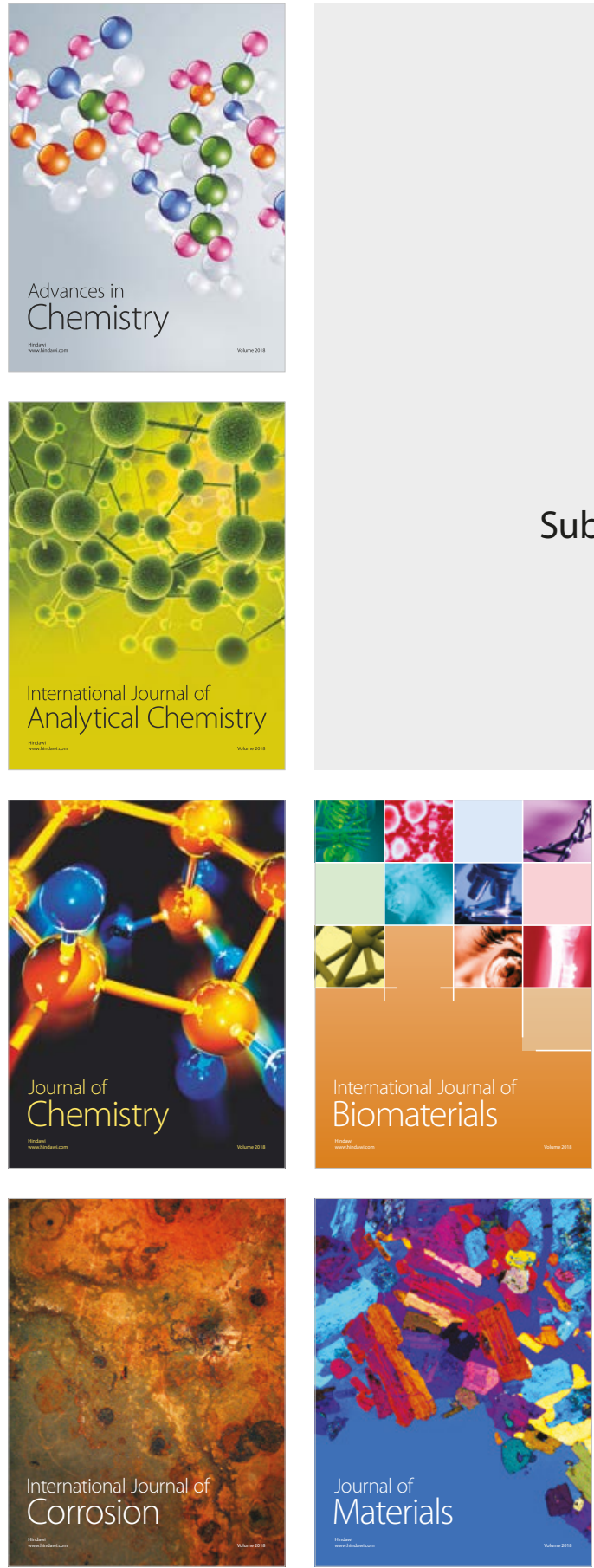

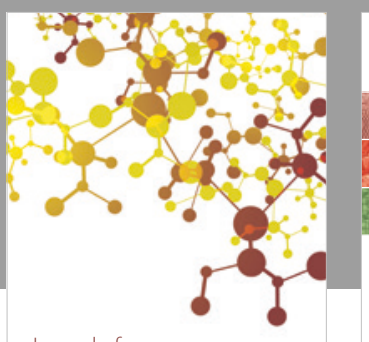

Journal of

Applied Chemistry
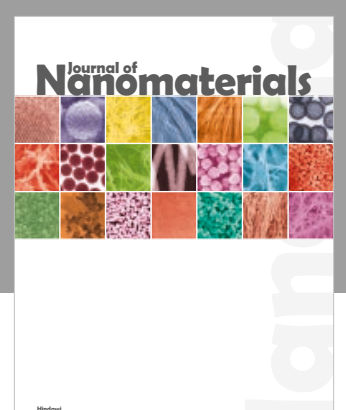

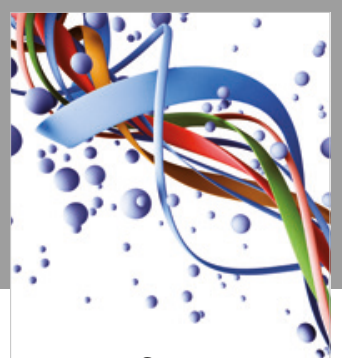

Scientifica

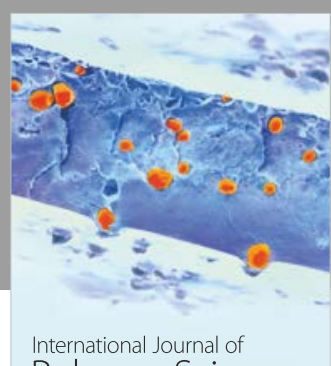

Polymer Science

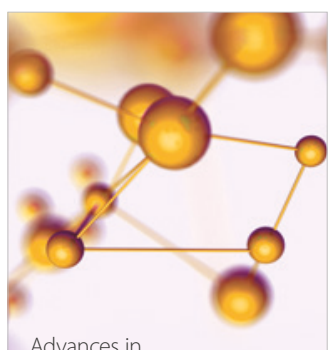

Physical Chemistry
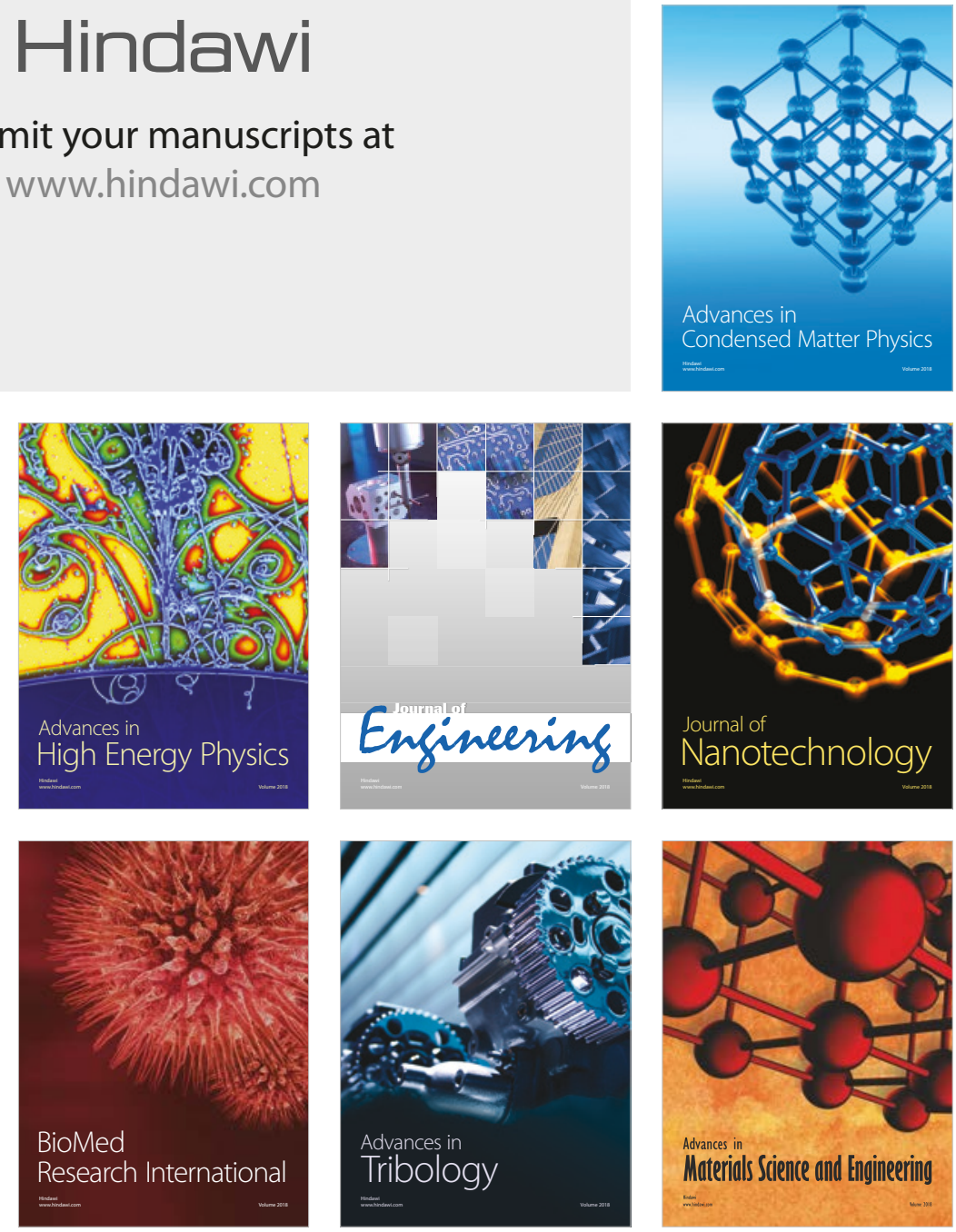